\title{
Utilization of Public Health and General Supervision Permits by Dental Hygienists in West Virginia
}

Lyndsey N. Gray

West Virginia University

Follow this and additional works at: https://researchrepository.wvu.edu/etd

\section{Recommended Citation}

Gray, Lyndsey N., "Utilization of Public Health and General Supervision Permits by Dental Hygienists in West Virginia" (2011). Graduate Theses, Dissertations, and Problem Reports. 3277.

https://researchrepository.wvu.edu/etd/3277

This Thesis is protected by copyright and/or related rights. It has been brought to you by the The Research Repository @ WVU with permission from the rights-holder(s). You are free to use this Thesis in any way that is permitted by the copyright and related rights legislation that applies to your use. For other uses you must obtain permission from the rights-holder(s) directly, unless additional rights are indicated by a Creative Commons license in the record and/ or on the work itself. This Thesis has been accepted for inclusion in WVU Graduate Theses, Dissertations, and Problem Reports collection by an authorized administrator of The Research Repository @ WVU. For more information, please contact researchrepository@mail.wvu.edu. 


\title{
Utilization of Public Health and General Supervision Permits by Dental Hygienists in West Virginia
}

\author{
Lyndsey N. Gray, BSDH
}

Thesis Submitted to the School of Dentistry

At

West Virginia University

In Partial Fulfillment of the Requirements for

The Degree of Master of Science in Dental Hygiene

Christina DeBiase, BSDH, MA, EdD, Chair

Amy Funk, BSDH, MSDH

Michael Hendryx, PhD

\author{
Morgantown \\ West Virginia \\ 2011
}

Keywords: Public Health Permit; General Supervision Permit;

Direct Supervision 


\begin{abstract}
Utilization of Public Health and General Supervision Permits by Dental Hygienists in West Virginia Lyndsey N. Gray
\end{abstract}

The issue of oral health in individuals has emerged as an immediate concern for many states to address, especially West Virginia. Current statistics show dental caries to be the most common chronic disease of children which has led to the development of such programs as The West Virginia Oral health Plan for 2010-2015. Plans such as this aim to develop techniques to provide improved oral care for all populations.

The purpose of the study is to examine if dental hygienists in West Virginia are utilizing their general supervision permits and dental hygiene public health permits to provide treatment to patients in public health settings. Surveys were sent to all dental hygienists licensed in West Virginia. Two separate mailings were utilized to distribute the surveys. A response rate of $32 \%$ was achieved. A statistician was utilized to analyze the data received.

The results revealed that the majority of the responding dental hygienists $(67.7 \%)$ have obtained the general supervision permit and less than $15 \%$ of licensed dental hygienists in West Virginia have not obtained the public health dental hygiene permit. There was not a wide variation on the practice settings where dental hygienists with both permits are currently working, because most are working in private dental offices and schools. Also, there was a common opinion apparent that revolved around the thought that if two new dental hygiene permits were available then there must also be an increase in access to care. Results also showed barriers such a lack of job opportunities that prohibit dental hygienists from providing treatment in the public health arena. 


\section{DEDICATION}

This research project is dedicated to my Mom and Dad, who have been a source of unconditional love, strength, support, and inspiration throughout my life. I would not be where I am today without you by my side. 


\section{ACKNOWLEDGEMENTS}

I would like to take this opportunity to thank the many individuals who have made this research project possible.

Dr. Christina DeBiase, my thesis committee chairman, for the time and patience to guide me through this project and for always having a word of encouragement to help me through the day.

Mrs. Amy Funk, thesis committee member, for her guidance and understanding provided through this project and five years of dental hygiene education. Thank you for dealing with all of my questions.

Dr. Michael Hendryx, thesis committee member, for his help and instruction provided for my thesis.

Dr. Gerry Hobbs, statistician, for his time and patience entering and analyzing data.

Dr. Susan Morgan for her support and time. Thank you for always having a smile for me.

Peggy Gray for her love and faith provided during this project. Thank you for standing by me always. Thank you for handling my stress and catastrophes with calmness. I am blessed to have you as a mother and best friend.

John Gray for his strength and support during my thesis. Thank you for your understanding and patience. I am blessed to have you as a father.

Nathan Beam and Lauren Namsupak for their encouragement and support throughout the research process. I am so lucky to call you friends.

School of Dentistry graduating class of 2011 for their support and interest in my research. Thank you for pushing me to complete the thesis.

Nicki Metts for collecting all of my surveys and answering all of my questions. 


\section{TABLE OF CONTENTS}

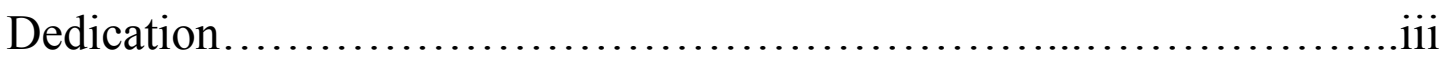

Acknowledgements.................................................

Table of Contents....................................................

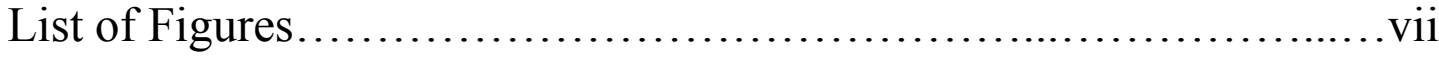

Chapter 1

Introduction................................................

State of the Problem.............................................2

Significance of the Study...................................2

Questions to be Answered.....................................4

Operational Definitions..................................... 5

Assumptions.................................................

Limitations.................................................6

Delimitations.............................................6

Chapter 2 Literature Review

Access to Care.................................................

Dental Therapist........................................... 8

Affiliated Practice Relationship..............................10

Advanced Dental Hygiene Practitioner........................11

Opposition to Dental Hygiene Licensure Advancement............12

Support of Dental Hygiene Licensure Advancement...............13 


\section{Chapter 3}

Methods and Materials........................................ 15

Results.................................................18

Discussion..............................................47

Conclusions................................................52

Recommendations..........................................54

Future Recommendations for Study..........................56

References.......................................................... 58 Appendices

Appendix A..............................................62

Appendix B............................................64

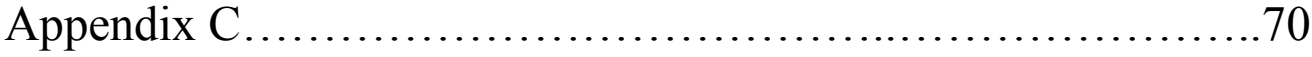

Appendix D.............................................. 73

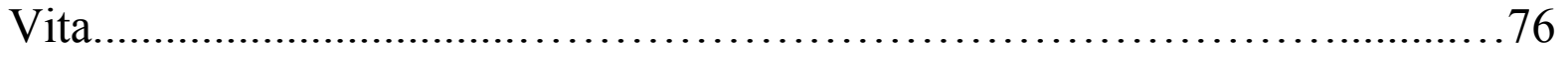




\section{List of Figures}

Figure 1 Number of Patients Treated Monthly Utilizing Direct Supervision

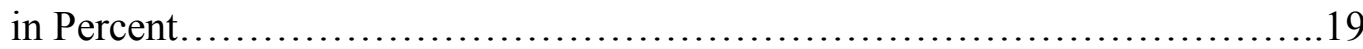

Figure 2 Practice Settings Utilizing Direct Supervision in Percent........................20

Figure 3 Patient Groups Treated by Dental Hygienists Utilizing Direct

Supervision in Percent.................................................21

Figure 4 Dental Procedures Provided Utilizing Direct Supervision in Percent.............23

Figure 5 Reasons Preventing Dental Hygienists from Obtaining Public

Health Dental Hygiene Permit and General Supervision Permit

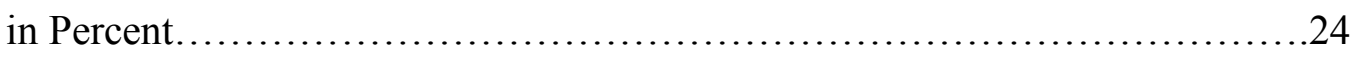

Figure 6 Percentage of Respondents who have Obtained a Public Health

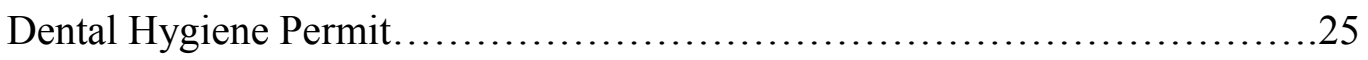

Figure 7 Previous Experience Treating Patients in a Public Health Setting

Before Acquiring the Public Health Dental Hygiene Permit

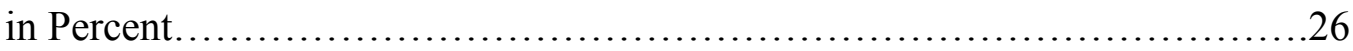

Figure 8 Type of Position Held by Dental Hygienists Practicing in a

Public Health Setting Before Acquiring the Public Health Dental

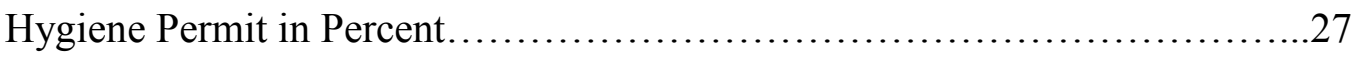

Figure 9 Percentage of Dental Hygienists with the Public Health Dental

Hygiene Permit who are Currently Treating Patients in a Public

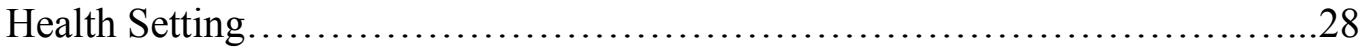

Figure 10 Types of Permits Utilized by Dental Hygienists Treating Patients

in a Public Health Setting in Percent...........................................29 
Figure 11 Barriers that Prevent Dental Hygienists with Public Health

Dental Hygiene Permit from Treating Patients in a Public Health

Setting in Percent....................................................... 30

Figure 12 Number of Patients Treated Monthly by Dental Hygienists

Utilizing the Public Health Dental Hygiene Permit in Percent...................31

Figure 13 Practice Settings Utilizing the Public Health Dental Hygiene

Permit in Percent........................................................ 32

Figure 14 Patients Groups Treated by Dental Hygienists Utilizing Public

Health Dental Hygiene Permit in Percent..................................33

Figure 15 Dental Procedures Provided Utilizing the Public Health Dental

Hygiene Permit in Percent.............................................. 34

Figure 16 Opinion Regarding Effect the Public Health Dental Hygiene

Permit has on Access to Care in Percent.................................. 35

Figure 17 Percentage of Respondents who have Obtained a General

Supervision Permit...................................................... 36

Figure 18 Previous Experience of Treating Patients in a Public Health

Setting Before Acquiring the General Supervision Permit

in Permit in Percent............................................................ 37

Figure 19 Type of Position Held by Dental Hygienists who Practiced in

a Public Health Setting Before Acquiring the General

Supervision Permit in Percent........................................... 38

Figure 20 Percent of Dental Hygienists with General Supervision Permit

and Currently Treat Patients in a Public Health Setting in Percent..............39 
Figure 21 Permits Utilized by Dental Hygienists Treating Patients in

a Public Health Setting in Percent............................................40

Figure 22 Barriers Preventing Dental Hygienists with the General

Supervision Permit from Treating Patients in a Public Health

Setting in Percent...................................................... 41

Figure 23 Number of Patients Treated Monthly Utilizing the General

Supervision Permit in Percent.....................................................42

Figure 24 Practice Settings of Dental Hygienists Utilizing the General

Supervision Permit in Percent................................................43

Figure 25 Patient Populations Treated by Dental Hygienists Utilizing

the General Supervision Permit in Percent........................................44

Figure 26 Types of Dental Procedures Provided Utilizing the General

Supervision Permit in Percent................................................... 45

Figure 27 Opinion Regarding Effect the General Supervision Permit

has on Access to Care in Percent...............................................46 


\section{CHAPTER 1}

\section{INTRODUCTION}

The issue of oral health in individuals has emerged as an immediate concern for many states to address, especially West Virginia. The Centers for Disease Control and Prevention (CDC) states that dental caries are the most common chronic disease of children aged 6 to 11

years and adolescents aged 12 to 19 years. ${ }^{1}$ According to CDC, in 2008 only $59.9 \%$ of West Virginia's population visited the dentist within the past year. ${ }^{2}$

These statistics have initiated development of programs and plans such as The West Virginia Oral Health Plan for 2010-2015, which was released by the West Virginia Bureau for Public Health. The plan identifies seven objectives focused around improving oral health. The objectives are:

1) Strengthen West Virginia's state level infrastructure and capacity to improve the oral health of its citizens

2) Develop a financing strategy for oral health services and implementation of the state plan recommendations

3) Promote oral health across the lifespan

4) Strengthen and improve the dental health workforce

5) Invest in community prevention

6) Strengthen the role of West Virginia's schools in promoting the oral health of students

7) Maintain, evaluate, and monitor state plan implementation ${ }^{3}$ 
Dental hygienists being given the opportunity to work in other settings besides private dental offices would help the dental workforce to meet some of the above objectives. In many areas such as New Zealand, Great Britain, Alaska, and Minnesota advanced duties and freedom to practice in community settings without a dentist being physically present have allowed access to care to increase for individuals. The purpose of the study is to examine if dental hygienists in West Virginia are utilizing their general supervision permit and public health dental hygiene permit to provide treatment to patients in public health settings. As a result of the study, the effectiveness of the general supervision and dental hygiene public health license will be assessed.

\section{STATEMENT OF THE PROBLEM}

Dental hygienists in West Virginia can obtain a general supervision permit and/or a dental hygiene public health permit in addition to a regular dental hygiene license that allows for direct supervision by the dentist. Currently, no data exists regarding how many dental hygienists with general supervision and public health dental hygiene permits work in settings other than private practices and what their job duties are in these settings. The absence of this information questions the outcomes of dental hygiene license advancement in West Virginia.

\section{SIGNIFICANCE OF THE STUDY}

In February 2009, a bill was passed in West Virginia allowing dental hygienists licensed in the state to also obtain a general supervision permit and a public health dental 
hygiene permit. The renewal cycle for 2010 was the first time dental hygienists practicing in West Virginia were required to report to the state dental board the types of dental services provided to patients while utilizing their general supervision and dental hygiene public health permits. The installation of these new permits has also brought out several questions and problems regarding the access to care and employment opportunities utilizing the general supervision and dental hygiene public health permits.

Dental hygienists practicing in West Virginia have provided the state dental board information regarding how many patients were treated, what types of services were provided, and what type of environments these services were provided in for the first time during the 2010 renewal cycle. Due to the fact this is the first year such information was reported to the state dental board there is currently no data that exists to assess if access to dental care in West Virginia has increased since the installation of these new permits. Without data addressing how many hygienists are effectively using their general supervision and public health dental hygiene permits and where they are using their permits there is no way of knowing if these permits are an asset for the state. Until statistics can be provided demonstrating an increase in access to care with the help of dental hygienists using their general supervision and public health dental hygiene permits, more advancements in licensure and access to care cannot progress forward.

Another issue arises concerning access to care when discussing general supervision and public health dental hygiene permits. Many dental hygienists practice outside a private dental office under the direct supervision of a dentist. When assessing access to dental care there needs to be a way to define the percentage of hygienists that practice under direct 
supervision of a dentist in a public health setting and the dental hygienists that practice in a public health setting utilizing their general supervision or public health dental hygiene permits. Once data is collected and analyzed it will suggest if access to care has increased, decreased or stayed the same with the addition of the general supervision and public health dental hygiene permits.

The implementation of the general supervision and public health dental hygiene permits also creates an employment issue. When dental hygienists obtain these two new permits there are currently no employment positions available that would allow dental hygienists to use their permit in a way that would increase access to care. Until positions are created that offer a monetary wage, it is highly unlikely that all dental hygienists that have their general supervision and public health dental hygiene permits will perform dental services in a public health setting for free. The lack of available dental hygiene positions in public health settings must also be taken into consideration when discussing access to dental care in West Virginia.

\section{QUESTIONS TO BE ANSWERED}

1. How are dental hygienists who have obtained a general supervision permit and a public health dental hygiene permit utilizing their licenses?

2. Has access to dental care in West Virginia increased since the general supervision permit and the public health dental hygiene permit have become available to dental hygienists? 
3. What job opportunities are available for dental hygienists who have obtained a general supervision permit and public health dental hygiene permit in public health settings?

4. What barriers prevent dental hygienists from obtaining a general supervision permit and a public health dental hygiene permit?

\section{OPERATIONAL DEFINITIONS}

Direct Supervision

General Supervision

Public Health Permit
Requires that a dentist be physically present while dental hygienists treat patients $^{4}$

Allows dental hygienists to provide care to patients while the dentist is out of the office for not more than fifteen consecutive days ${ }^{4}$ Allows dental hygienists to practice in a public health environment ${ }^{4}$

\section{ASSUMPTIONS}

1. All dental hygienists participating in the study are currently licensed in West Virginia.

2. All dental hygienists responding to the survey understood the definitions and questions. 
3. There is a need for dental hygienists to practice under general supervision in community settings.

\section{LIMITATIONS}

1. Survey response

2. Human error in interpreting survey responses

3. Opinions of respondents

\section{DELIMITATIONS}

Surveys were sent to all dental hygienists licensed in West Virginia $(\mathrm{n}=844)$. Only the first mailing of survey responses will be used in the data due to the fact there was an error involved in the second mailing of surveys. 


\section{CHAPTER 2}

\section{REVIEW OF LITERATURE}

\section{ACCESS TO CARE}

Each year, millions of productive hours are lost due to dental illness. ${ }^{1}$ Children missed nearly 52 million hours of school and workers lost more than 164 million hours due to lack of treatment for dental disease. ${ }^{1}$ Access to oral health care in America is an issue. The Oral Health in America: A Report of the Surgeon General described "a silent epidemic of oral disease that is affecting the most vulnerable citizens including poor children, the elderly, and many members of racial and ethnic minority groups," and suggested that many Americans are unable to achieve optimal oral health due to barriers including lack of access to care. ${ }^{5}$ There are many access to care barriers patients face that affect everyone in the dental office. The barriers include: the patient's inability to pay for needed treatment, lack of transportation to a treatment facility or lack of available dental appointments, an inadequate number of practitioners, state laws that prevent practitioners from providing care in settings that are accessible to the patient, and special needs of the patient that prevent them from accessing care. ${ }^{6}$

Several of the barriers noted above could be decreased or eliminated with a few changes in dental care. The dental hygiene profession is projected to grow much faster than the average for all occupations through the year 2012. ${ }^{7}$ Since the dental hygiene profession will be growing at a fast rate there will be an increase in the number of dental hygienists in the workforce. Expanding the scope of practice to include providing treatment in public health settings utilizing general supervision would help to eliminate barriers such as: 
inadequate number of practitioners, state laws that prevent practitioners from providing care in facilities that are accessible to patients, lack of available dental appointments and lack of transportation to a facility. In the past five years, nine states have revised the scope of dental practice to allow a dental hygienist to initiate treatment based on his or her assessment of the patient's needs without specific authorization of a dentist and to treat the patient without the presence of a dentist. ${ }^{8}$ Throughout this literature review the concept of dental hygienists as mid-level providers will be discussed.

\section{DENTAL THERAPIST}

Many places have adopted the term dental therapist to describe their dental hygiene mid-level provider. Areas such as: New Zealand, Great Britain, Canada, Alaska, and Minnesota employ dental therapists. The dental therapist mid-level providers for each area will be separately described in the following paragraphs.

The New Zealand dental therapist originated in 1921. A group of 30 "dental nurses" began a two-year training program sponsored by the New Zealand federal government to address high levels of dental disease in children. ${ }^{9}$ During the first year topics of study include the basic biomedical sciences and clinical dental sciences. ${ }^{10}$ The second year course content includes pulpal pathology, trauma, extraction of primary teeth, clinical oral pathology, developmental anomalies, health promotion/disease prevention, the oral health care delivery system, record keeping, and administrative and legal issues associated with clinical care. ${ }^{10}$ The dental therapist cares for a large amount of the children in New Zealand. 
Almost $98 \%$ of New Zealand's children are enrolled in the School Dental Service where care is funded by the government and performed by the dental therapist. ${ }^{10}$

The dental therapist educational program was reintroduced in New Cross, England in 1963, having previously existed as early as $1916 .{ }^{11}$ The dental therapist in Great Britain functions similarly to the dental therapist in New Zealand. Dental hygiene programs implemented a dual-degree program so students could graduate from a program in dental hygiene and dental therapy. ${ }^{11}$ Students educated in this program also received extensive laboratory instruction on models and separate clinic time with live patients to perfect their restorative skills. ${ }^{11}$ The New Cross school closed in 1983. By 1989, only $19.1 \%$ of these dental therapists were still practicing due to the profession's poor financial return. ${ }^{11}$

In 1972, training at the National School of Dental Therapy in Canada began. ${ }^{9}$ The dental therapist for Canada was designed in order to provide oral health care to isolated communities within Canada under general supervision of a licensed dentist. ${ }^{9}$ Dental therapists in Canada are currently allowed to provide treatment to any age group. Many of the procedures dental therapists in Canada provide to the community are irreversible. ${ }^{9}$

The Dental Health Aide Therapist (DHAT) in Alaska was created to increase access to care for Alaskan natives. DHATs were created so natives who live in the remote areas of Alaska could be provided oral health care. The DHATs currently serving in Alaska have been educated at the University of Otago, New Zealand. ${ }^{8}$ The DHAT program focuses on prevention, pain and infection relief, and basic restorative services. ${ }^{8}$ A dentist is responsible for writing the standing orders, providing general supervision, and being the point of contact for the therapist. ${ }^{8}$ 
In 2009 Minnesota also began to train mid-level providers. The dental therapist and advanced dental therapist became the state's first mid-level providers on May 16, 2009. ${ }^{12}$ Education of the mid-level providers occurs at the University of Minnesota. The dental therapists are trained to provide some basic preventive services, limited restorative services, extractions of primary teeth, and have limited prescriptive authority. ${ }^{12}$ Dental therapists are able to administer services without the dentist on site, but all restorative services, extractions and services that are more involved would require the presence of a dentist. ${ }^{12}$ The advanced dental therapist evaluates, assesses and treatment plans, performs nonsurgical extractions of permanent teeth and all services of a dental therapist but without the requirement of onsite supervision. ${ }^{12}$ Dental therapists and advanced dental therapists both work under a collaborative management agreement with a dentist. ${ }^{12}$

\section{AFFILIATED PRACTICE RELATIONSHIP}

In 2004, the Arizona legislation approved HB 2194 as law, which created a new opportunity for children to access preventive dental services offered by a dental hygienist without the direct supervision or prior examination of a licensed dentist. ${ }^{13}$ The new law allows dental hygienists to work in collaboration with dentists. Every affiliated practice dental clinic in Arizona has a different structure and unique partners, such as hospitals, elementary schools, community health centers, county health departments, Indian Health services, dental schools and dental hygiene schools. ${ }^{13}$ Affiliated Practice models are more cost-effective than traditional dental practices due to elimination of a dentist's salary, smaller staff needed, fewer instruments and equipment required, and malpractice insurance fees are 
lower. ${ }^{13}$ Eligibility for entering an affiliated practice requires an active license, an established affiliated practice relationship with a specific licensed dentist, and have held a dental hygiene license for five years and actively engaged in dental hygiene for at least 2,000 hours in the five years immediately preceding the affiliated practice relationship. ${ }^{14}$

\section{ADVANCED DENTAL HYGIENE PRACTITIONER}

The Advanced Dental Hygiene Practitioner (ADHP) is an expanded function dental hygiene model that, as currently proposed, would provide diagnostic, preventive, restorative, and therapeutic services directly to the public in rural and underserved areas. ${ }^{8}$ The American Dental Hygienists' Association began to develop the ADHP model in 2004. An ADHP is a dental hygienist who has graduated from an accredited dental hygiene program and has completed an advanced educational curriculum, approved by the American Dental Hygienists' Association. ${ }^{15}$

The ADHP would have the authority to practice without the supervision of a dentist, and would mirror many of the same services performed by dentists. ${ }^{9}$ The scope of practice for the ADHP includes but is not limited to the following: ${ }^{8}$

- Health education, counseling, and health promotion

- Diagnosis, treatment, and referral of oral disease and conditions within a multidisciplinary care team

- Cavity preparation

- Pulpotomies 
- Extractions

- Palliative therapy

- Atraumatic restorative therapy

- Pain management strategies

- Nutritional interventions

- Prescription writing for select medications

- Evaluation of health promotion and disease prevention programs for specific populations

- Case management

- Consultation/collaboration with other professionals

\section{OPPOSITION TO DENTAL HYGIENE LICENSURE ADVANCEMENT}

Many have spoken out regarding opposition to dental hygiene licensure advancement. The Academy of General Dentistry (AGD) and The American Academy of Pediatric Dentistry (AAPD) Taskforce on Workforce Issues have shared concerns regarding the American Dental Hygiene Practitioner model. ${ }^{9}$ The Pennsylvania Dental Association has also expressed concerns with the public health dental hygiene license in Pennsylvania by implying that patient safety would be placed at risk if dental hygienists were allowed to practice unsupervised. ${ }^{16}$

In a letter to the editor in the September/October 2009 issue of Pediatric Dentistry, Pitts Hinson discusses his opposition to dental hygiene mid-level providers. He states, "The role of primary care is not a role to be filled by mid-level providers, but by dentists and 
physicians trained to deliver comprehensive care to our population." ${ }^{18}$ He does not feel that it is in the best interest of children or adults of our country to be offered a dual-standard of care whether it is regarding dentistry or medicine. ${ }^{18}$

\section{SUPPORT OF DENTAL HYGIENE LICENSURE ADVANCEMENT}

Improving the oral health status of the U.S. population is a significant challenge to policy makers, health officials, dental educators, and dental care providers. ${ }^{13}$ One way to expand preventive dental services to underserved populations is by allowing dental hygienists to provide preventive services with less restrictive supervision in underserved

communities. ${ }^{13}$ Although some do oppose dental hygiene licensure advancement there many who support the advancement.

Many see the benefits of having dental hygienists employed in schools, nursing homes, and retirement facilities. In these facilities dental hygienists could begin daily fluoride mouthrinse programs, provide dental hygiene services to individuals on a regular basis, and refer patients to dentists for necessary treatments. ${ }^{16}$ Other benefits of having a dental hygienist present in these facilities include oral health treatment, oral cancer examinations, appropriate recommendations and referrals, cost savings achieved, and an increase in disease prevention. ${ }^{16}$

In the Pediatric Dentistry journal for November/December 2009, Dr. David Nash wrote about the importance of oral health therapists in the dental office. According to the American Dental Association, the four most common procedures in a pediatric dentist's 
office are periodic oral exams, bitewing radiographs, prophylaxis, and topical fluoride therapy. ${ }^{17}$ Nash argues that, we do not need, nor can we afford as a nation, to continue to train pediatric dentists with an average earning of $\$ 338,000$, to accomplish primary care procedures that years of experience has demonstrated can be safely and effectively provided by individuals with two years of education. ${ }^{17}$ 


\section{CHAPTER 3}

\section{METHODS AND MATERIALS}

An online application to conduct the research study was submitted and accepted for exempt status by the Institutional Review Board of West Virginia University. The exemption can be found in Appendix A. A 24 question survey was mailed to a convenience sample that included the entire population of dental hygienists licensed in West Virginia. The survey can be found in Appendix B. A list of dental hygienists licensed in West Virginia that was current as of February 2010 was used for the mailing list in the study.

The five page survey was mailed to each dental hygienist with a self addressed, business reply envelope. Two mailings were utilized for this study. A two page cover letter was included with the survey. The cover letter for the first and second mailing and can be found in Appendix C and D, respectively. The cover letter explained that the purpose of the research was to examine how dental hygienists in West Virginia treat patients in various types of practice settings and also to address barriers dental hygienists encounter when trying to practice in a public health setting. Public health dental hygiene permit, general supervision permit, and direct supervision were defined in the cover letter to ensure that the participants possessed a consistent understanding of the permits and their differences. The cover letter also stated the research was being conducted to partially fulfill requirements for a master's degree in dental hygiene. The expectations of voluntary participation was also addressed within the cover letter. 
The estimated time listed on the cover letter to complete the survey was 15 minutes. The cover letter for the first mailing was sent on November 17, 2010 and participants were asked to return the survey in the envelope provided by December 13, 2010. The cover letter for the second mailing was sent on January 3, 2011 with a return response by February 4, 2011.

The top of the survey listed instructions for completing the survey. The survey consisted of 20 multiple choice questions and four open ended questions. Seven questions asked the participants to simply answer yes or no. Two questions included yes, no, and do not know as answer choices. Four questions included only two answer options and seven questions asked the participants to check all that apply. Of those seven questions, four of them had other as an option with a space provided for a more detailed explanation. Participants who were not actively practicing dental hygiene were asked to answer question one and then skip to question nineteen. Information requested on the survey included:

- Practicing status

- Permits obtained (public health dental hygiene permit and general supervision permit)

- Previous experience in public health setting and whether the position was paid or volunteer

- Currently practicing in public health setting

- Barriers that prevent dental hygienists from treating patients in a public health setting

- Reasons why permits have not been obtained 
- Average number of patients treated with direct supervision, public health dental hygiene permit, and general supervision permit

- Environments where dental hygienists are currently practicing utilizing direct supervision, public health dental hygiene permit, and general supervision permit

- Patient groups being treated by dental hygienists practicing with direct supervision, public health dental hygiene permit, and general supervision permit

- Services being provided by dental hygienists utilizing direct supervision, public health dental hygiene permit, and general supervision permit

- Participants' thoughts regarding access to care in West Virginia

- Participants' thoughts regarding public health dental hygiene permit

- Participants' thoughts regarding general supervision permit

Data from each survey was entered into an Excel spreadsheet once received. The data was then sent to a statistician to be analyzed. Results were reported in percents, frequencies, and cumulative frequencies. 


\section{RESULTS}

A response rate of $32.0 \%(n=273)$ was obtained for the study. Currently, as of February 2010, 45 dental hygienists in West Virginia had obtained the public health dental hygiene permit. The majority (35) of those dental hygienists with the public health dental hygiene permit responded to the survey which yielded a response rate of $78 \%$ for this permit. The February 2010 renewal cycle also showed that 451 dental hygienists licensed in West Virginia have obtained the general supervision permit. Close to $40 \%$ (178) of the dental hygienists with the general supervision permit responded to the survey. Almost all of the respondents (95.6\%) were actively practicing dental hygiene at the time the survey was completed. All of the dental hygienists in West Virginia practice under direct supervision due to the nature of the license. Therefore, all responding dental hygienists were supposed to answer questions pertaining to direct supervision as well as questions that pertained to any dental hygiene permits they may have obtained. The following graphs represent the results from each survey question. The first subsection will discuss direct supervision. The next subsection will be categorized into the two dental hygiene permits available, public health dental hygiene permit and general supervision permit.

\section{Direct Supervision}

Five questions on the survey focus on direct supervision of the dental hygienist. The majority $(86.1 \%)$ of practicing dental hygienists stated that they treat 31 or more patients in a month. See Figure 1. 
Figure 1: Number of Patients Treated Monthly Utilizing

Direct Supervision in Percent $(n=245)$

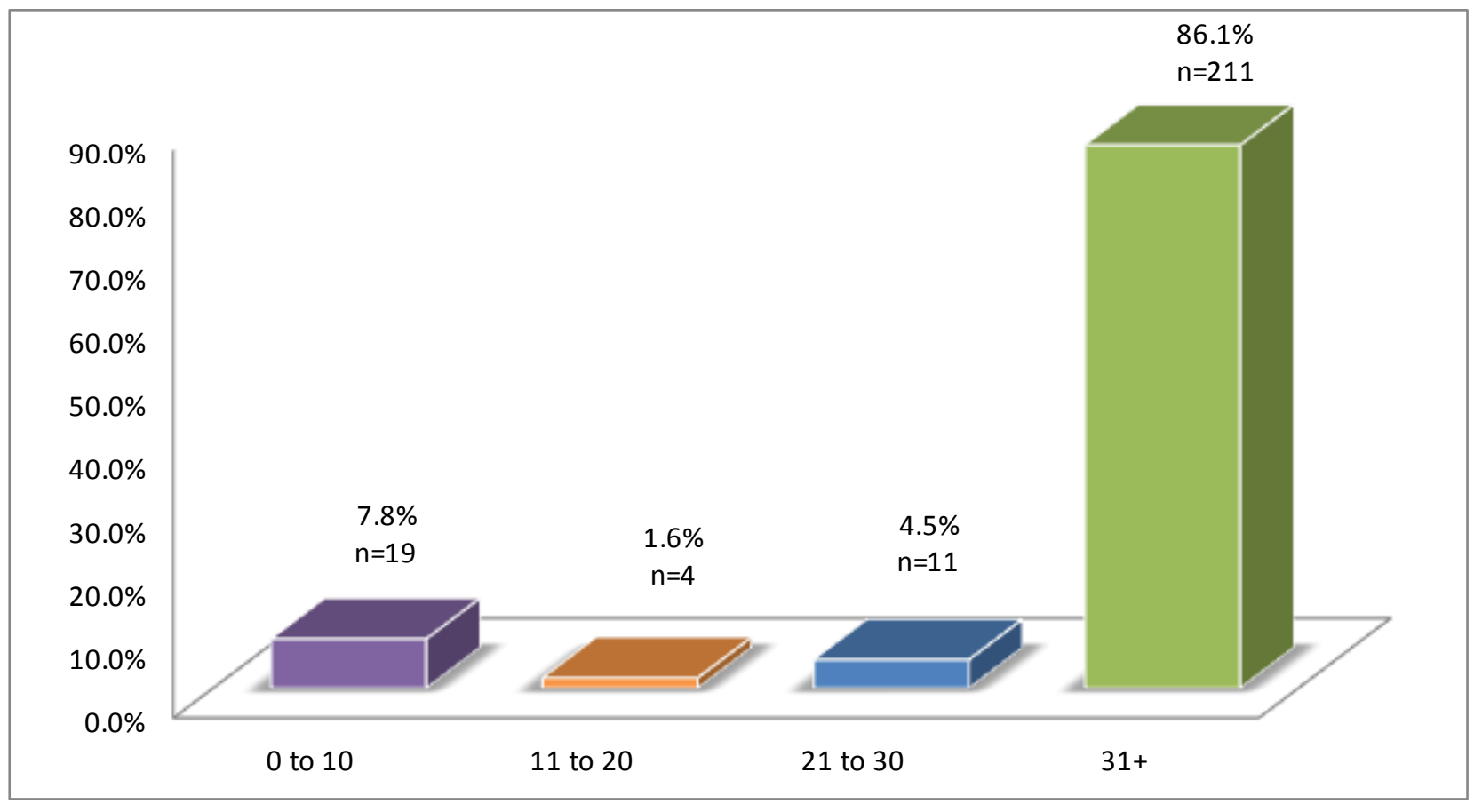

Most (85.2\%) respondents utilizing direct supervision indicated that they currently practice in a private dental office. The second most common (6.1\%) place of practice for respondents was schools. The environment where the least amount $(0.38 \%)$ of dental hygienists are currently practicing is long-term facilities. Responses for the other category included educational settings, orthodontic offices, and head start facilities. See Figure 2. 


\section{Figure 2: Practice Settings Utilizing Direct Supervision in Percent (n=264)}

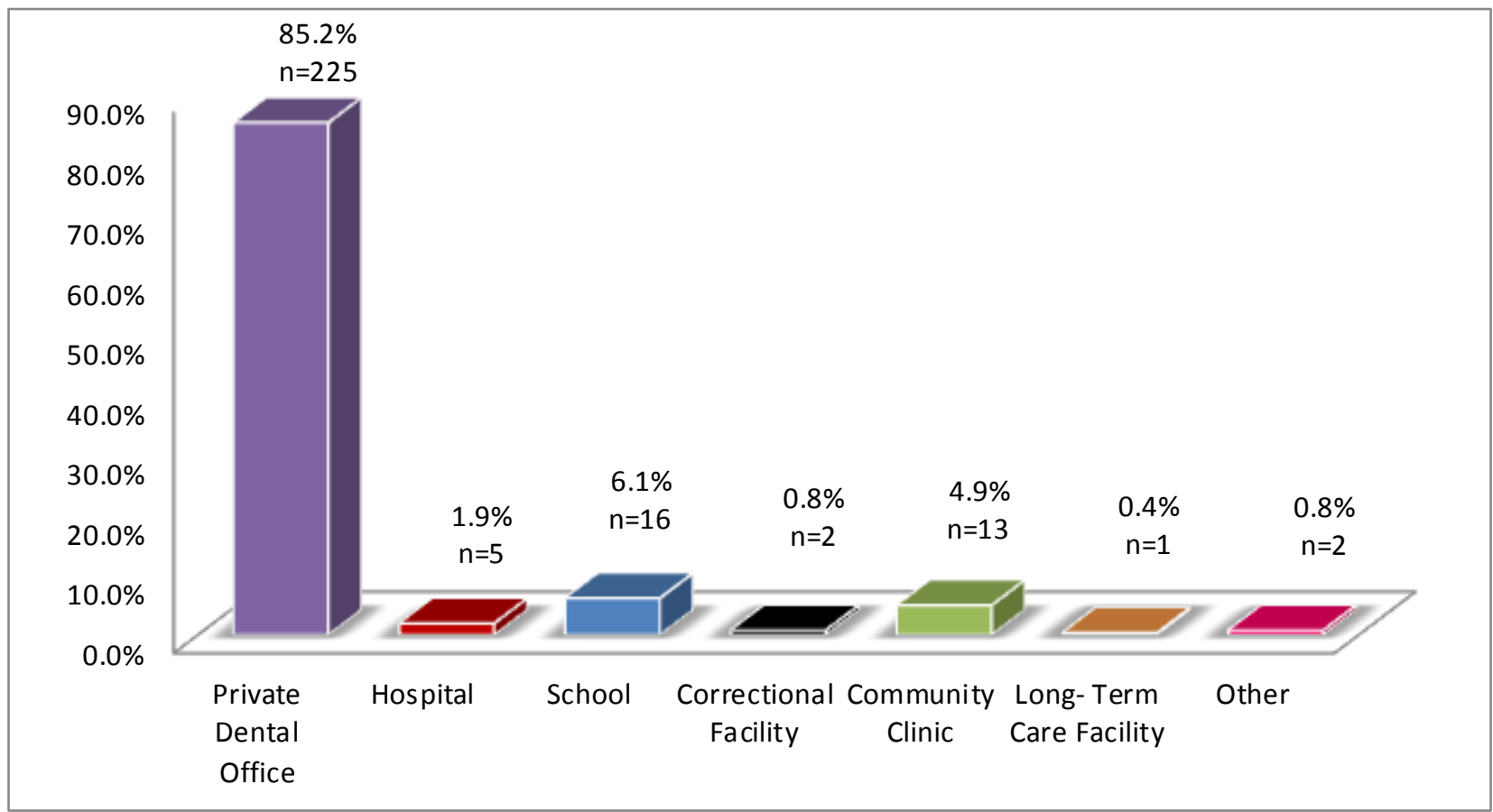

*Percentages do not equal 100 due to ability of respondents to check all that apply

Dental hygienists currently treat all types of patient groups including:

- Preschool children (newborn to 4)

- $\quad$ School aged children (5-18)

- $\quad$ Adults (19-64)

- $\quad$ Senior citizens $(65+)$

- Medically compromised 
The majority of respondents $(97.6 \%)$ treat adults, senior citizens $(96.4 \%)$, and school aged children (94.8\%). Most of the respondents also treat preschool children (86.3\%) and medically compromised patients $(84.7 \%)$ while utilizing direct supervision. See Figure 3.

\section{Figure 3: Patients Groups Treated by Dental Hygienists Utilizing Direct}

\section{Supervison in Percent $(n=247)$}

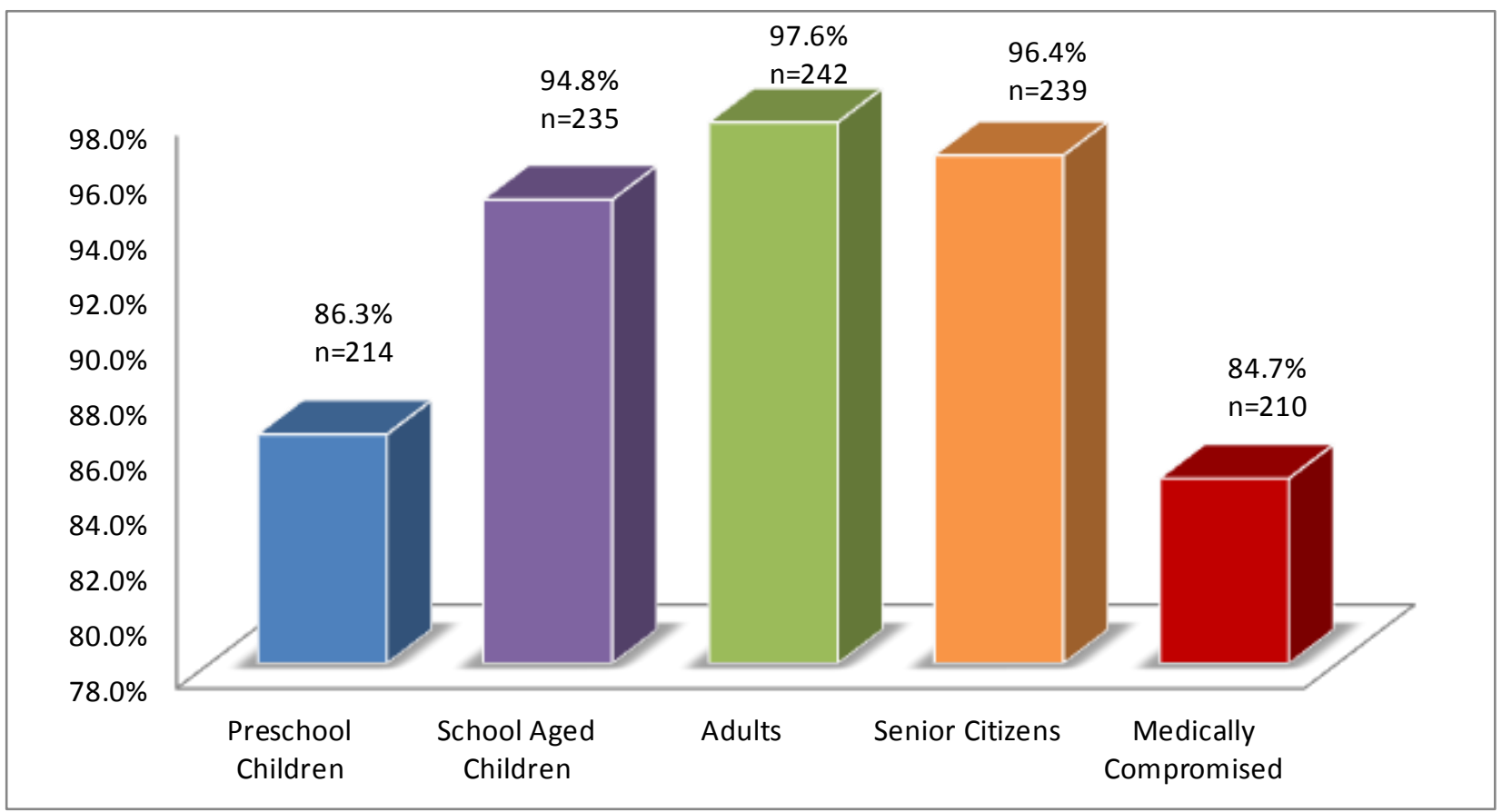

*Percentages do not equal 100 due to ability of respondents to check all that apply

One question on the survey addressed what procedures are being completed by dental hygienists utilizing direct supervision. The top dental procedures currently being performed include dental health education (99.6\%), place, expose, develop, and mount radiographs (99.2\%), dental prophylaxis $(99.2 \%)$, record medical and dental histories $(98.8 \%)$, examine 
and record periodontal findings (98\%), debridement/root planing of teeth $(95.2 \%)$, and chart existing restorations and missing teeth $(95.2 \%)$. The two least performed procedures include removal of loose orthodontic bands and brackets (33.6\%) and finish and polish restorations (26.4\%). See Figure 4. 


\section{Figure 4: Dental Procedures Provided Utilizing Direct Supervision in}

\section{Percent $(\mathbf{n}=250)$}

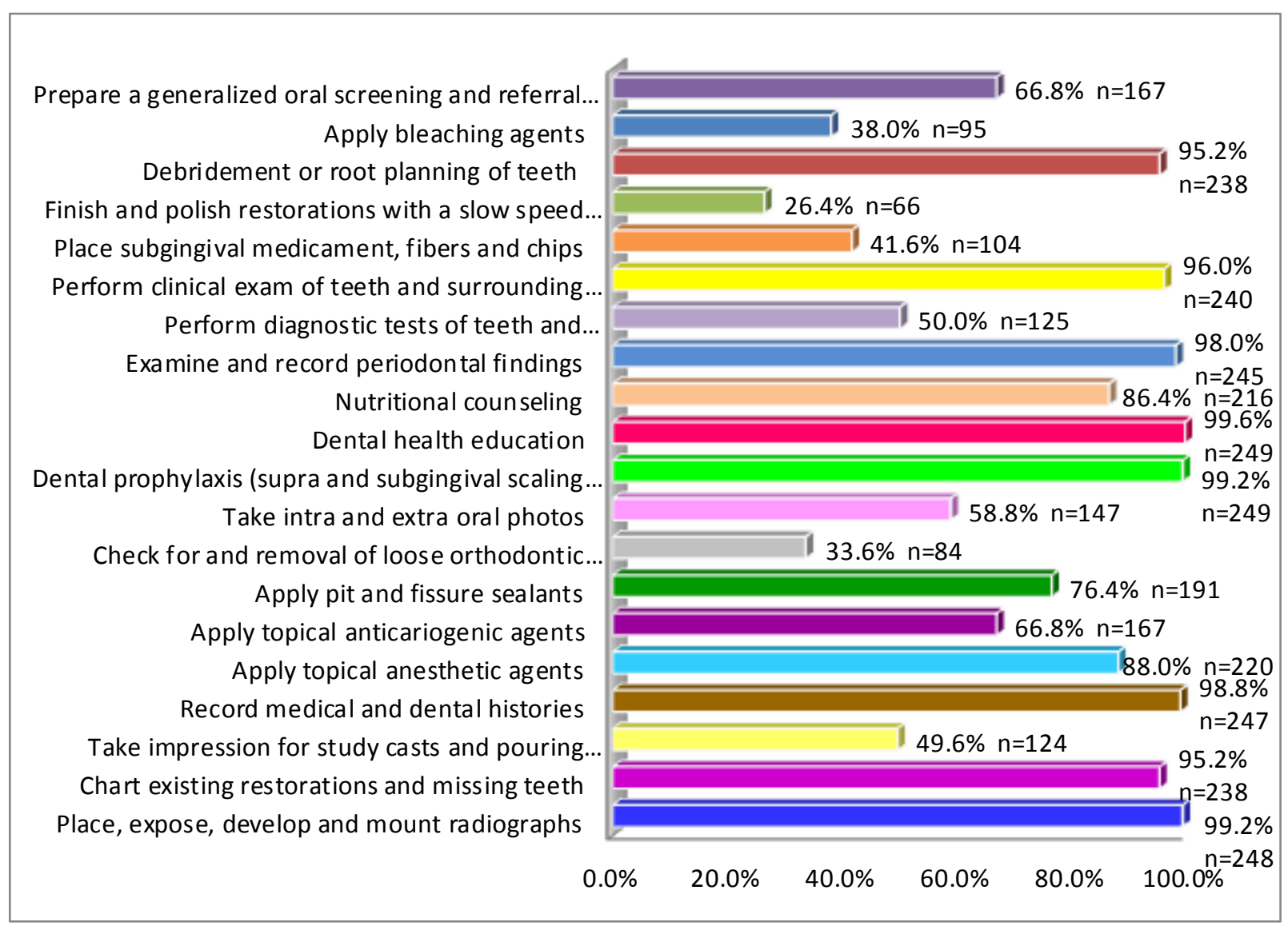

*Percentages do not equal 100 due to ability of respondents to check all that apply

One question asked dental hygienists utilizing direct supervison why they do not currently have the public health dental hygiene permit and general supervision permit. The top two responses to this question were no interest in obtaining these permits $(30.7 \%)$ and prerequistes have not been met (29.1\%). Common answers listed for the other category included no need for permits at current job, currently pursing permits, only working part-time so no need for permits, and unaware of permits currently available. See Figure 5. 


\section{Figure 5: Reasons Preventing Dental Hygienists from Obtaining Public}

\section{Health Dental Hygiene Permit and General Supervision Permit in Percent}

$$
(\mathbf{n}=127)
$$

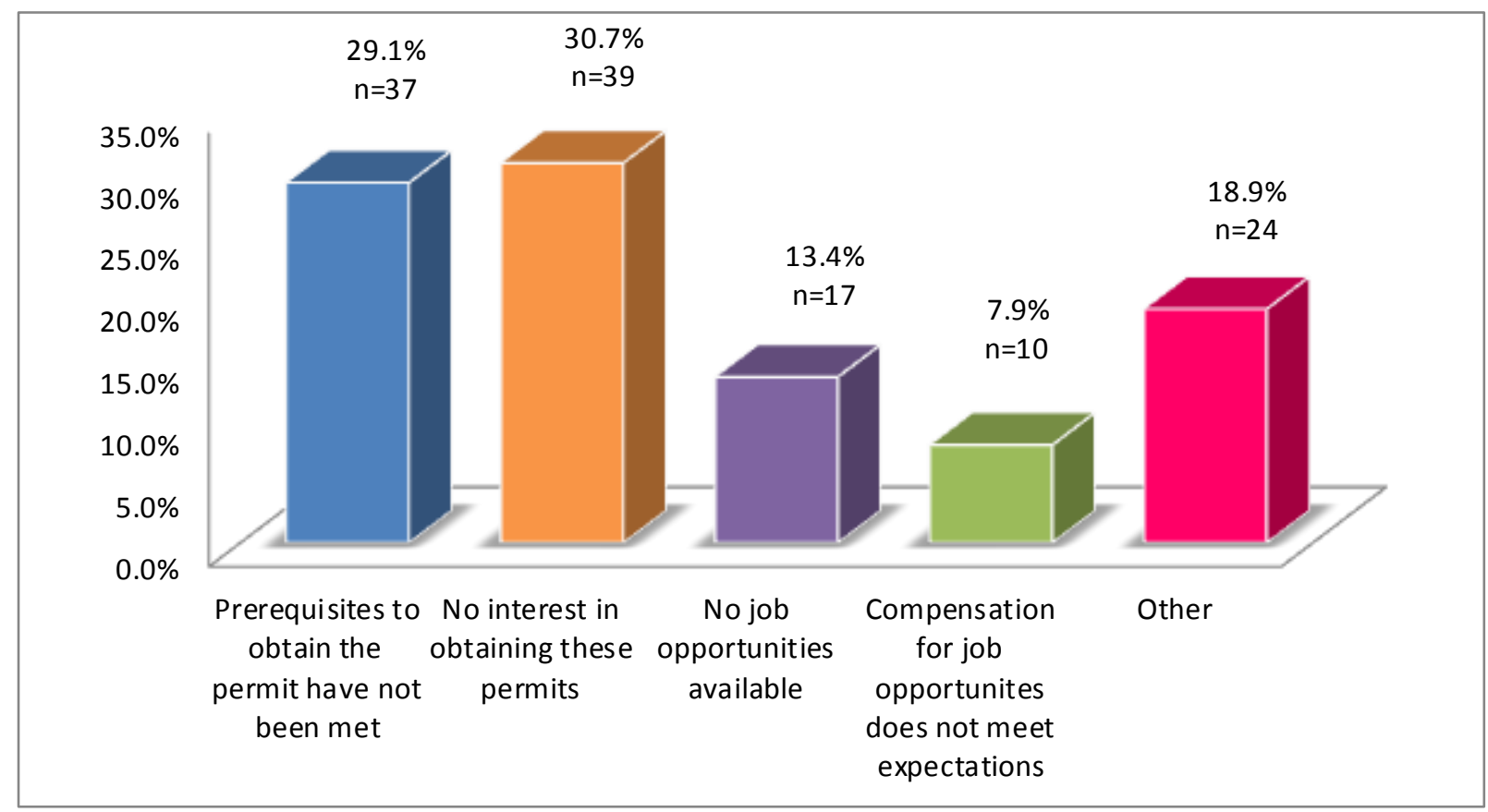

*Percentages do not equal 100 due to ability of respondents to check all that apply

\section{Public Health Dental Hygiene Permit}

Eleven questions on the survey correspond to the public health dental hygiene permit. The majority $(86.5 \%)$ of the respondents indicated they did not have the public health dental hygiene permit. See Figure 6. The dental hygienists responding that they did have the public health dental hygiene permit $(n=35)$ indicated that the majority $(76 \%)$ did not treat patients 
in a public health setting before acquiring the permit. See Figure 7. The majority (73.3\%) who did practice in public health settings before acquiring the permit held paid positions. See Figure 8 . Only $26 \%$ of the respondents are currently treating patients in a public health setting and of these respondents $78.6 \%$ of them are utilizing their public health dental hygiene permit while providing treatment to these patients. See Figures 9 and 10

Figure 6: Percentage of Respondents who have Obtained a Public Health Dental Hygiene Permit $(\mathbf{n}=259)$

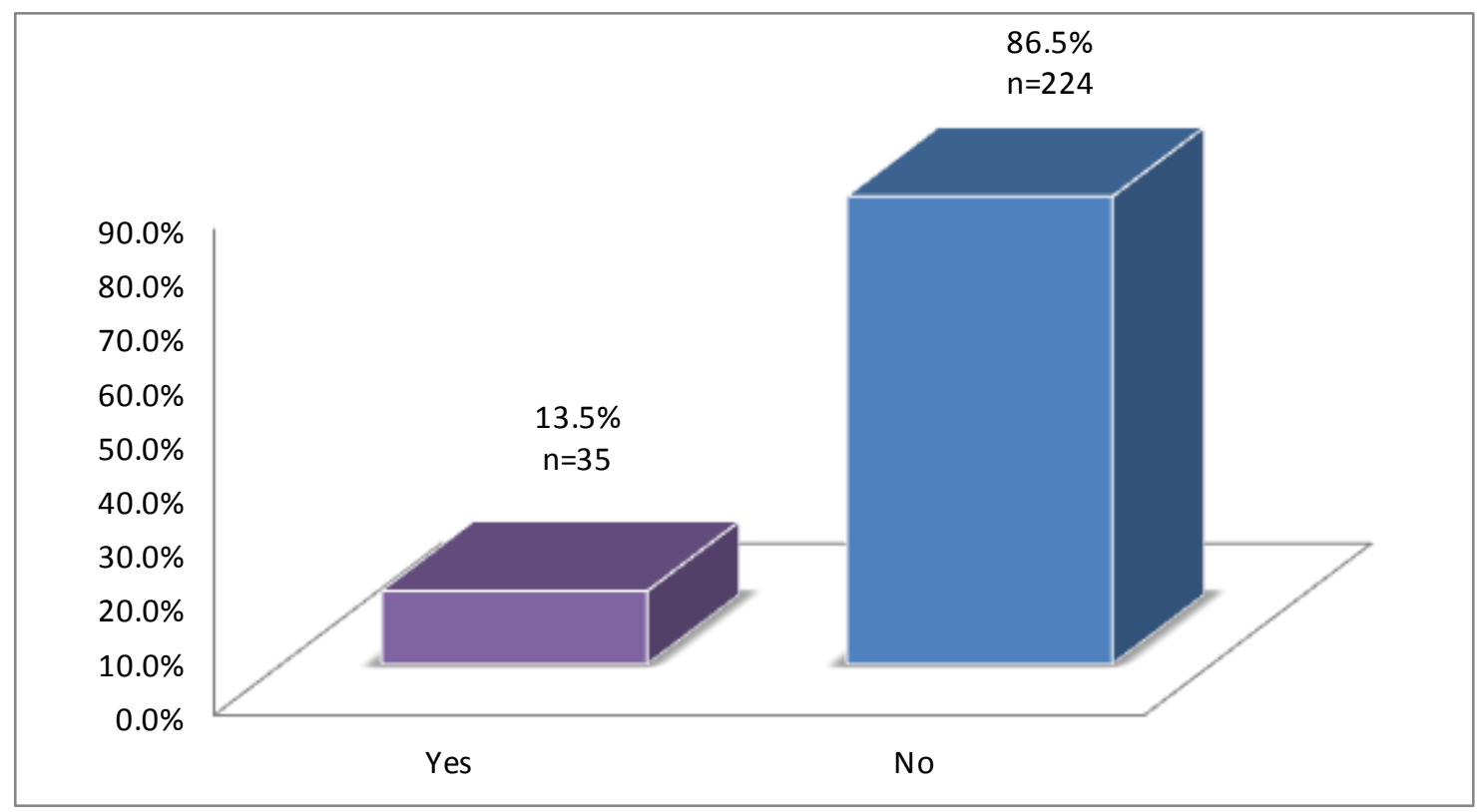


Figure 7: Previous Experience Treating Patients in a Public Health Setting Before Acquiring the Public Health Dental Hygiene Permit in Percent $(\mathbf{n}=50)$

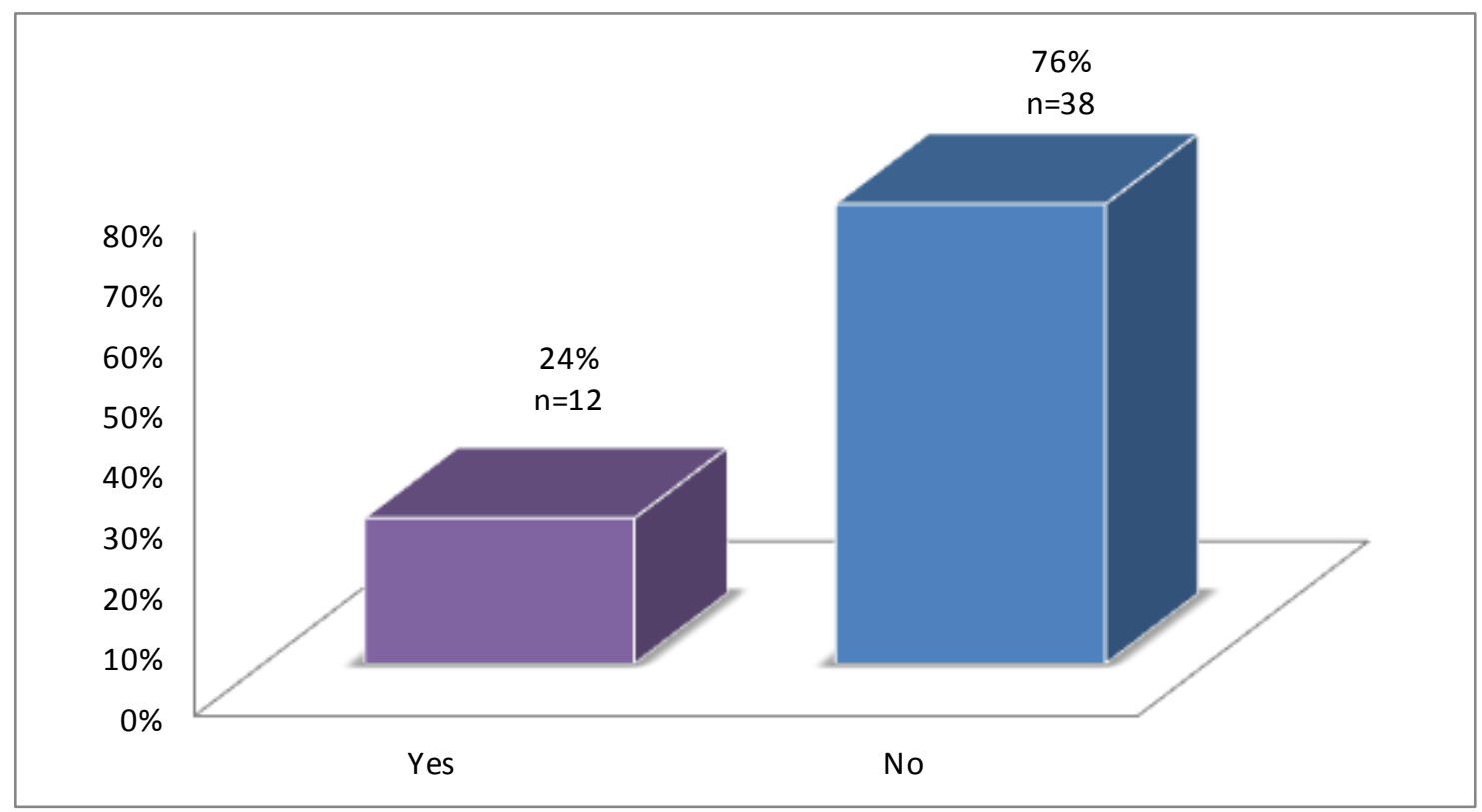


Figure 8: Type of Postion Held by Dental Hygienists Practicing in a Public Health Setting Before Acquiring the Public Health Dental Hygiene Permit in Percent $(\mathbf{n}=15)$

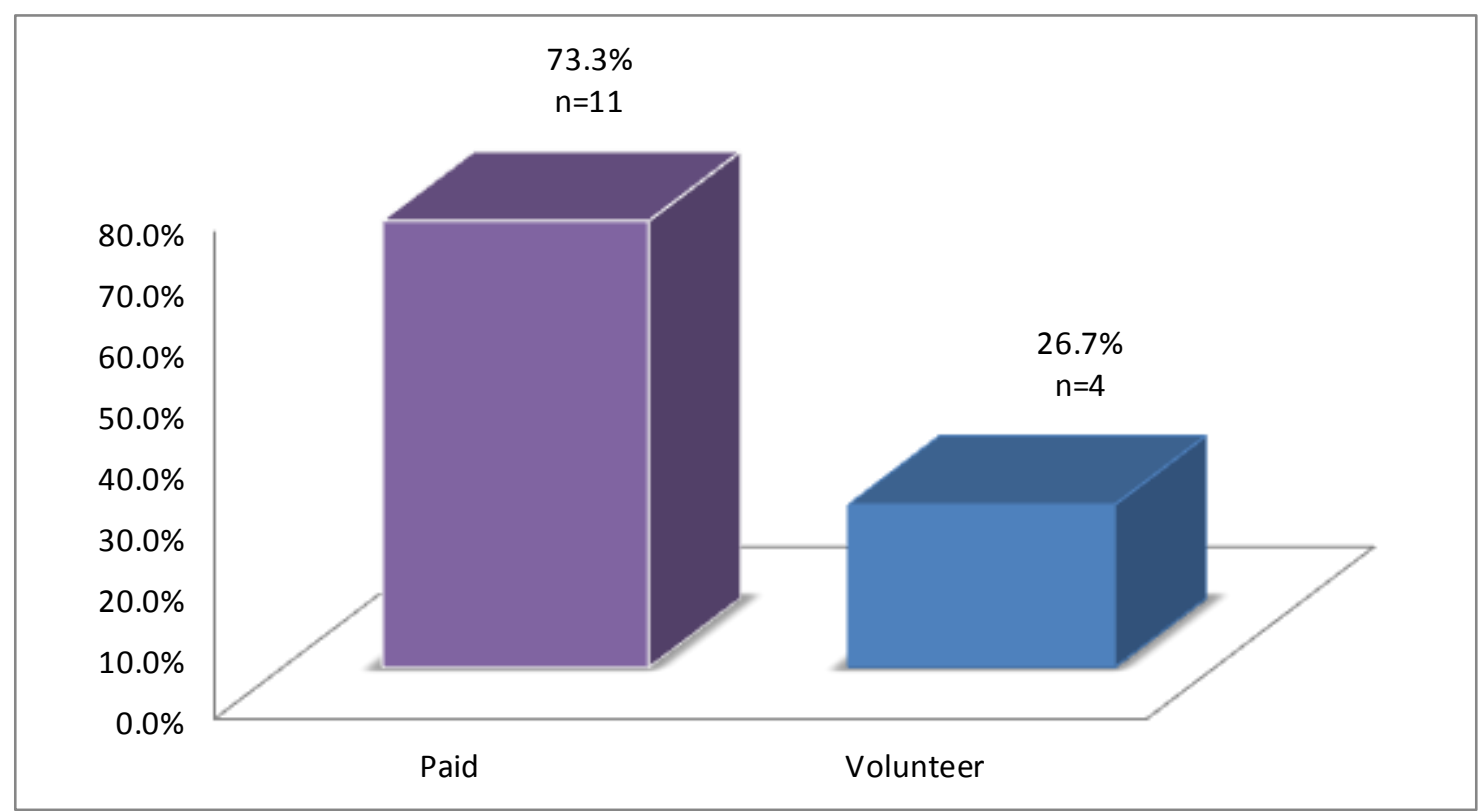


Figure 9: Percentage of Dental Hygienists with the Public Health Dental Hygiene Permit who are Currently Treating Patients in a Public Health Setting $(\mathbf{n}=50)$

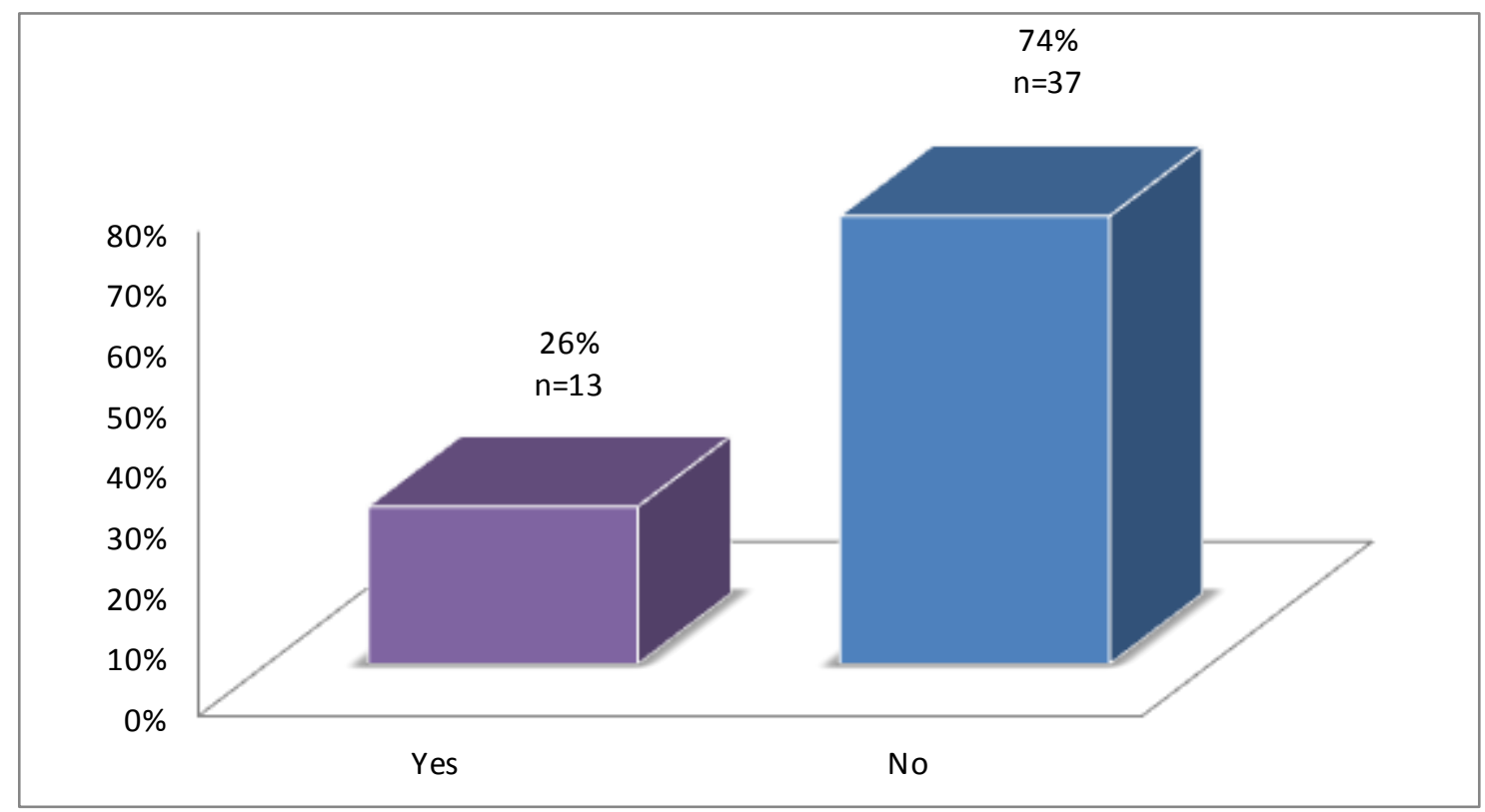




\section{Figure 10: Types of Permits Utilized by Dental Hygienists Treating}

Patients in a Public Health Setting in Percent $(n=14)$

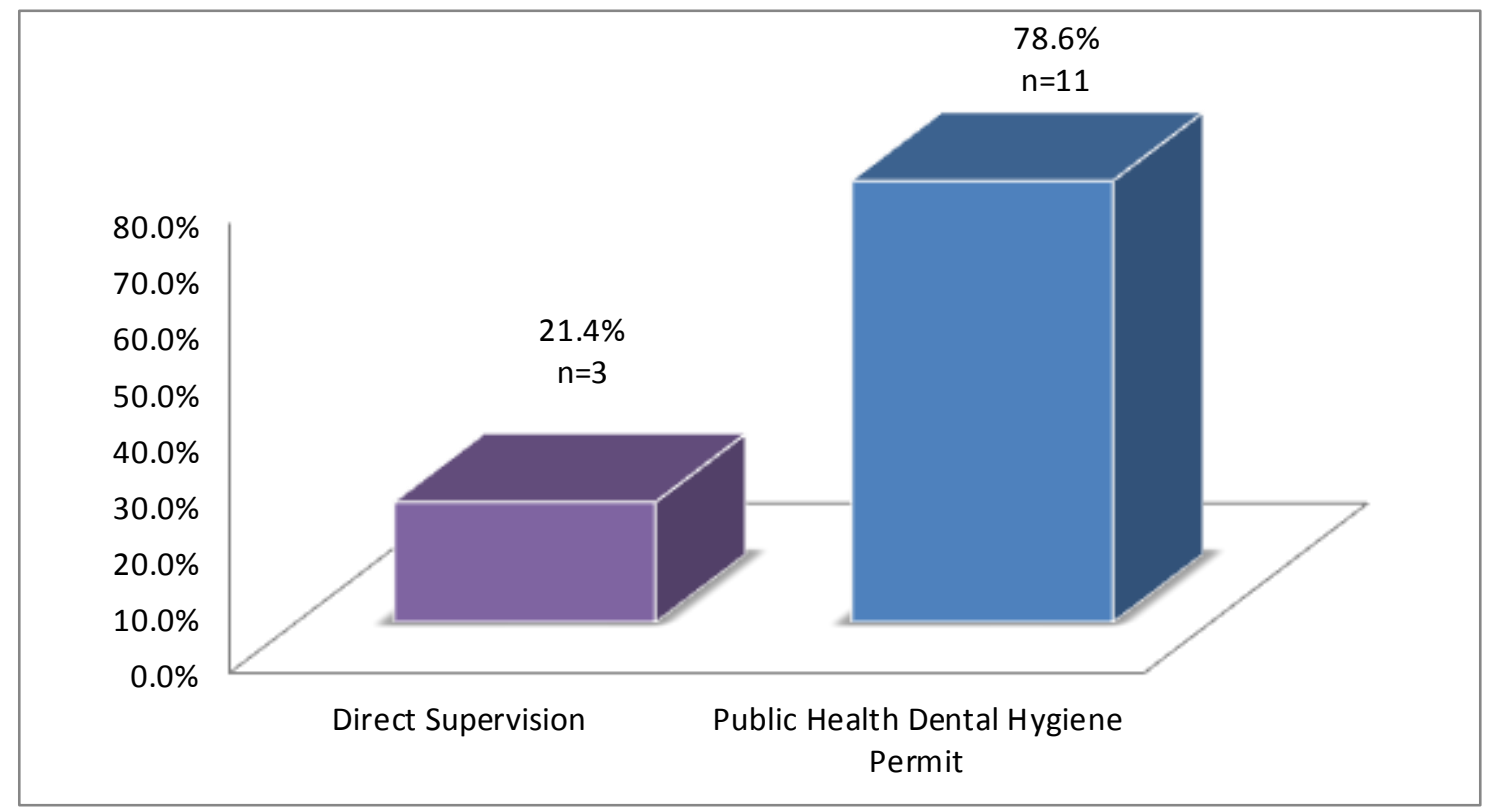

One survey question addressed the barriers that prevent dental hygienists from treating patients in a public health setting. The top two reasons cited for barriers were lack of job opportunities available (37.1\%) and employer is not associated with any public health agencies $(35.7 \%)$. Common answers to the other category included currently working in a full-time position in a private dental practice and no desire to obtain permit. See Figure 11. 
Figure 11: Barriers that Prevent Dental Hygienists with Public Health

\section{Dental Hygiene Permit from Treating Patients in a Public Health Setting in}

\section{Percent (n=70)}

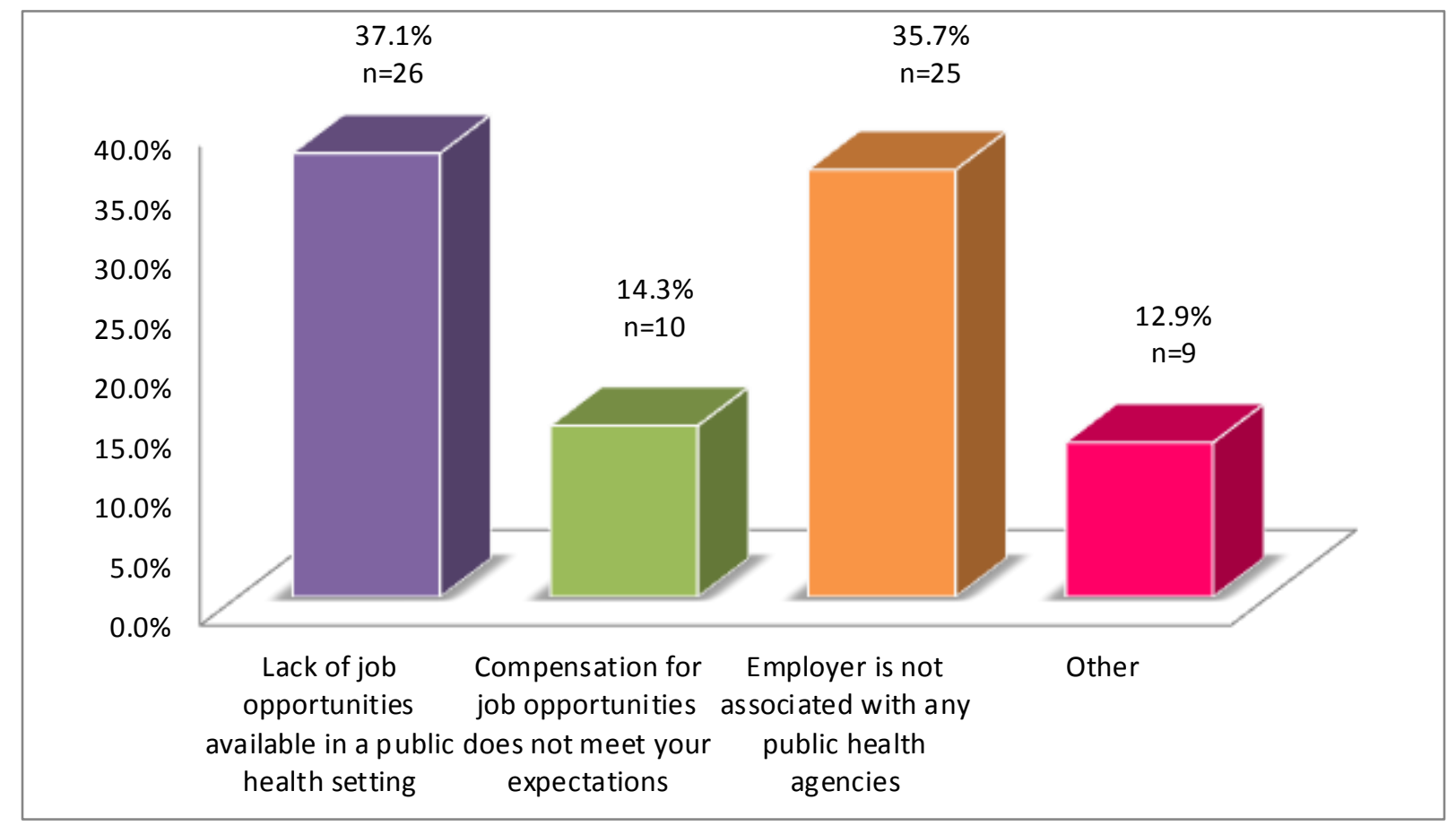

*Percentages do not equal 100 due to ability of respondents to check all that apply

The majority (84.4\%) of the dental hygienists reported they are treating less than 10 patients in a month utilizing the public health dental hygiene permit. Only $8.9 \%$ of the respondents are treating 31 or more patients in a month. See Figure 12. 
Figure 12: Number of Patients Treated Monthly by Dental Hygienists

Utilizing the Public Health Dental Hygiene Permit in Percent $(n=45)$

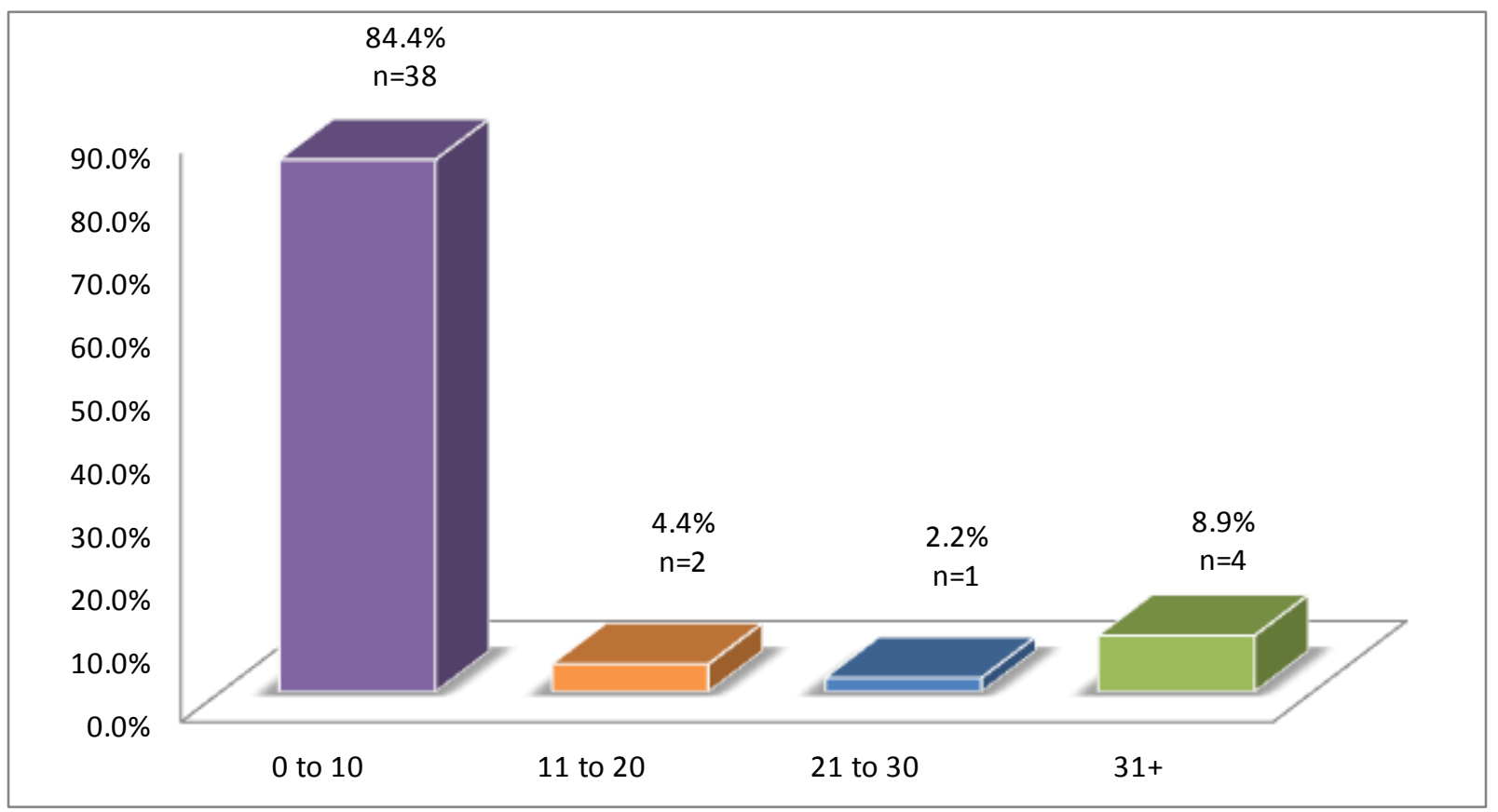

The respondents utilizing the public health dental hygiene permit frequently reported that they are currently practicing in schools (30.8\%) and community clinics $(23.1 \%)$. See Figure 13. 


\section{Figure 13: Practice Settings Utilizing the Public Health Dental Hygiene}

\section{Permit in Percent $(n=26)$}

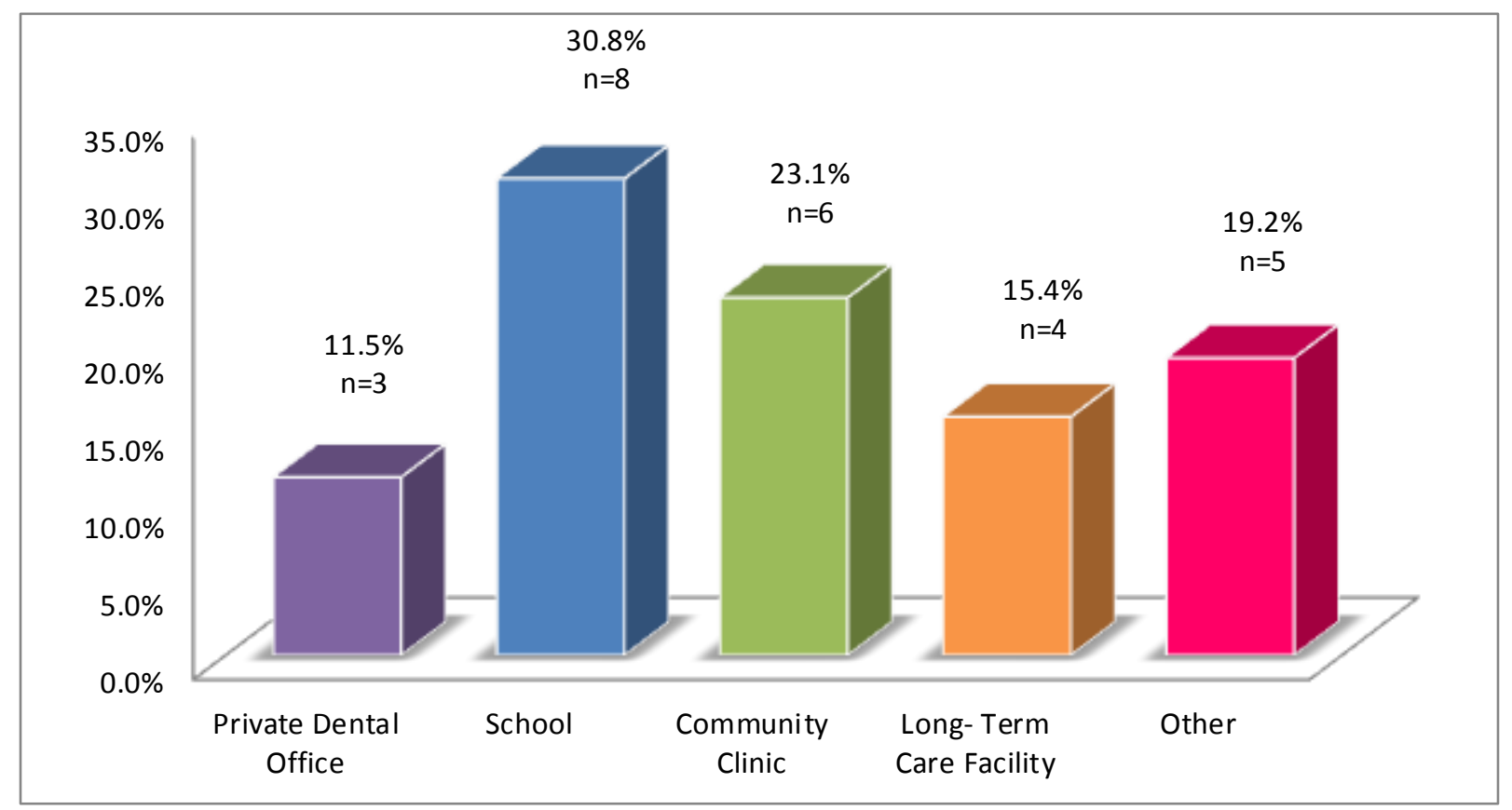

*Percentages do not equal 100 due to ability of respondents to check all that apply

Respondents utilizing the public health dental hygiene permit were also questioned about the type of patients they treat. The group designations remained the same as the groups for direct supervision. The majority of the respondents indicated they treated school aged children (68.8\%) and preschool children (56.3\%). Most of the respondents also provide treatment to adults (50\%), senior citizens (43.8\%), and medically compromised $(43.8 \%)$ patients. See Figure 14. 


\section{Figure 14: Patients Groups Treated by Dental Hygienists Utilizing Public}

\section{Health Dental Hygiene Permit in Percent $(\mathbf{n}=15)$}

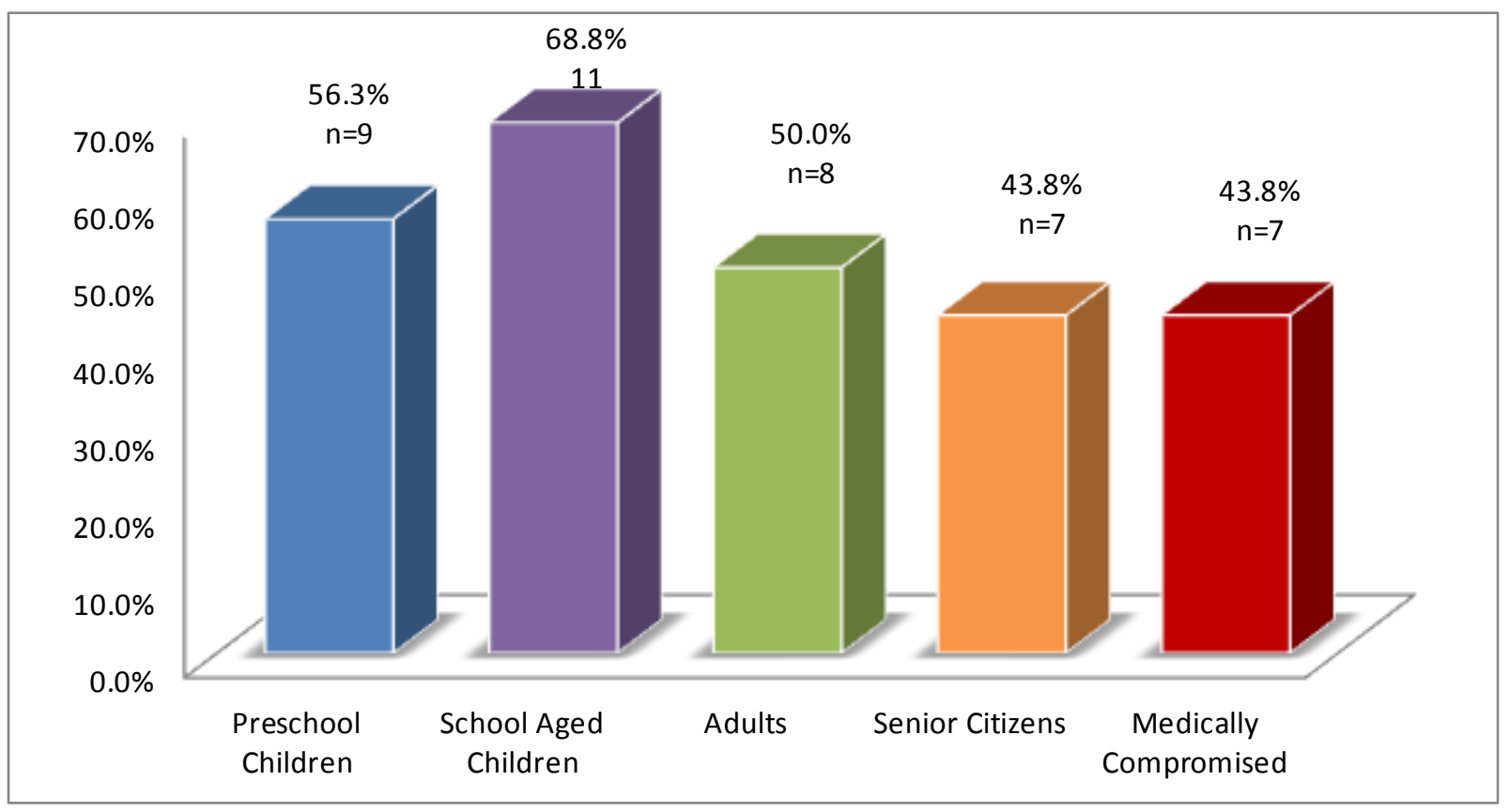

*Percentages do not equal 100 due to ability of respondents to check all that apply

Respondents were quieried about what procedures they are currently providing using the public health permit. Every respondent $(n=18)$ who answered this question indicated that they are providing dental health education to patients. The majority of the respondents are also preparing a generalized oral screening (88.9\%), nutritional counseling $(77.8 \%)$, and recording medical and dental histories (72.2\%). See Figure 15. 


\section{Figure 15: Dental Procedures Provided Utilizing the Public Health Dental}

\section{Hygiene Permit in Percent $(n=18)$}

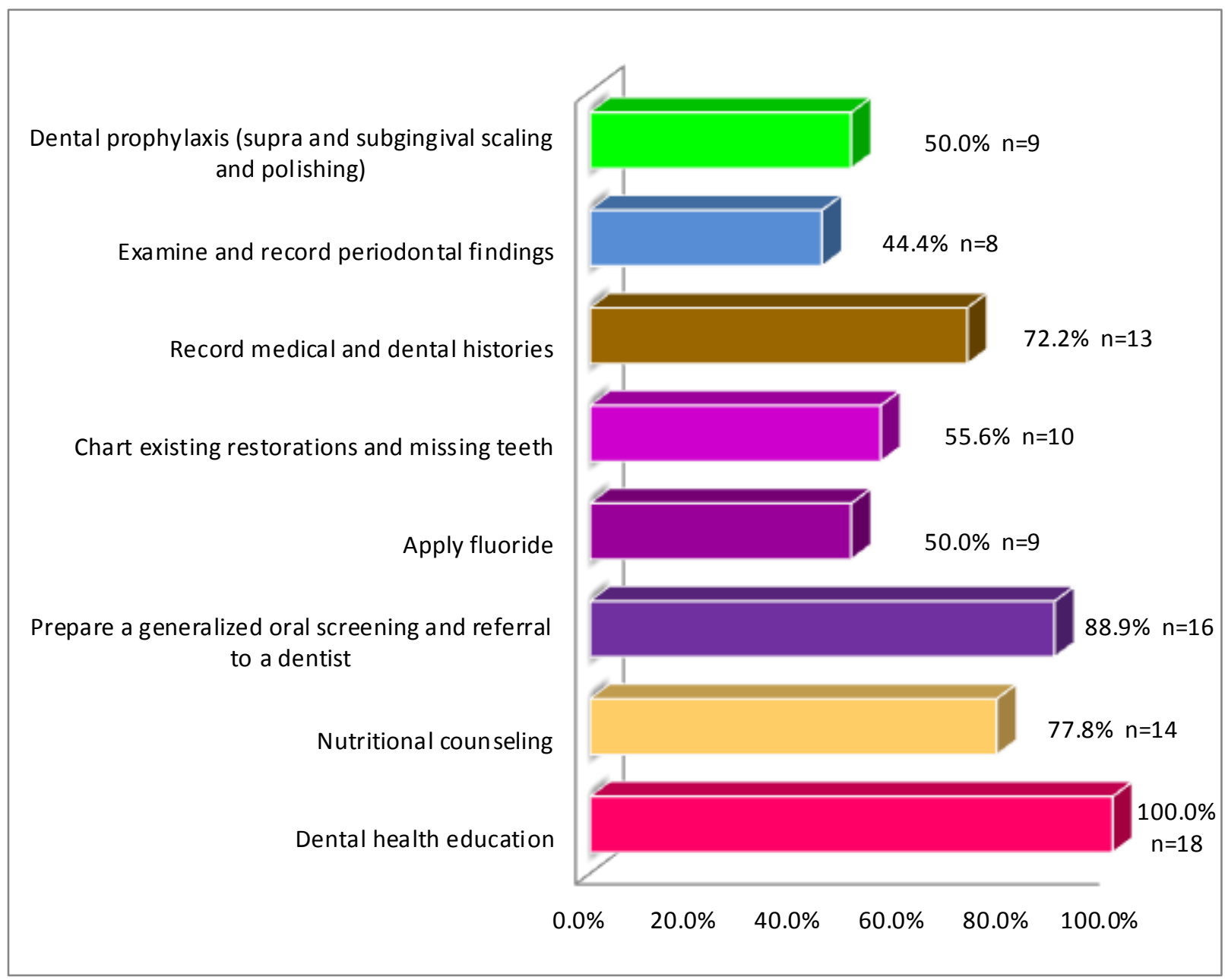

*Percentages do not equal 100 due to ability of respondents to check all that apply 
Finally, the respondents were asked to indicate if they felt access to care has increased since the public health dental hygiene permit became available. The majority (63.7\%) of the respondents chose the "do not know" option. The "yes" option was chosen by $23.2 \%$ and "no" was selected by $13.1 \%$ of the respondents. See Figure 16.

Figure 16: Opinion Regarding Effect the Public Health Dental Hygiene

Permit has on Access to Care in Percent $(n=267)$

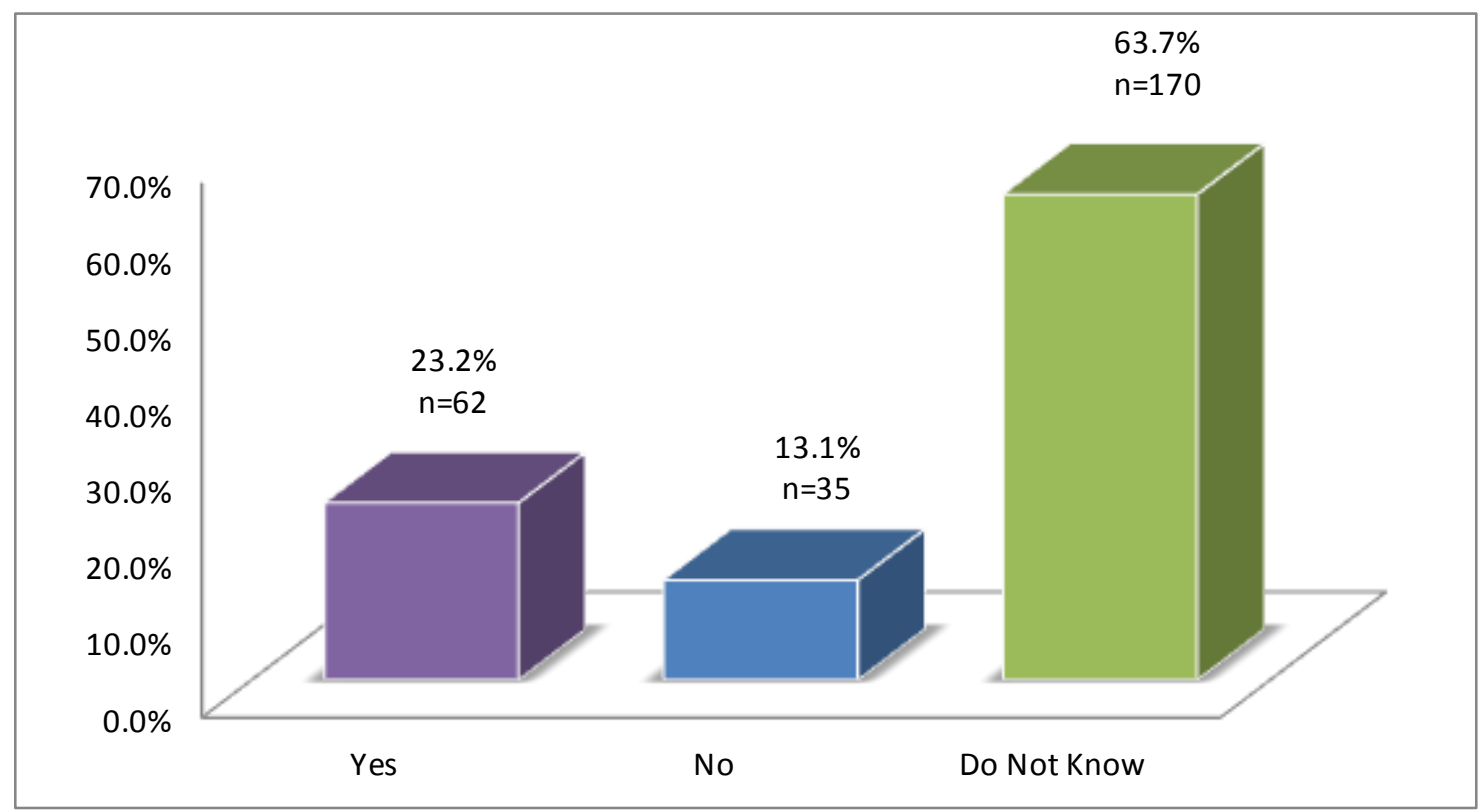




\section{$\underline{\text { General Supervision Permit }}$}

Eleven questions on the survey pertained to the general supervision permit.

Respondents were first asked if they had their general supervision permit. The majority $(67.7 \%)$ of the respondents possess a general supervision permit. See Figure 17. Currently 451 dental hygienists licensed in West Virginia possess a general supervision permit and 178 of the hygienists with this permit responded to the survey.

\section{Figure 17: Percentage of Respondents who have Obtained a General}

\section{Supervision Permit $(\mathrm{n}=\mathbf{2 6 3})$}

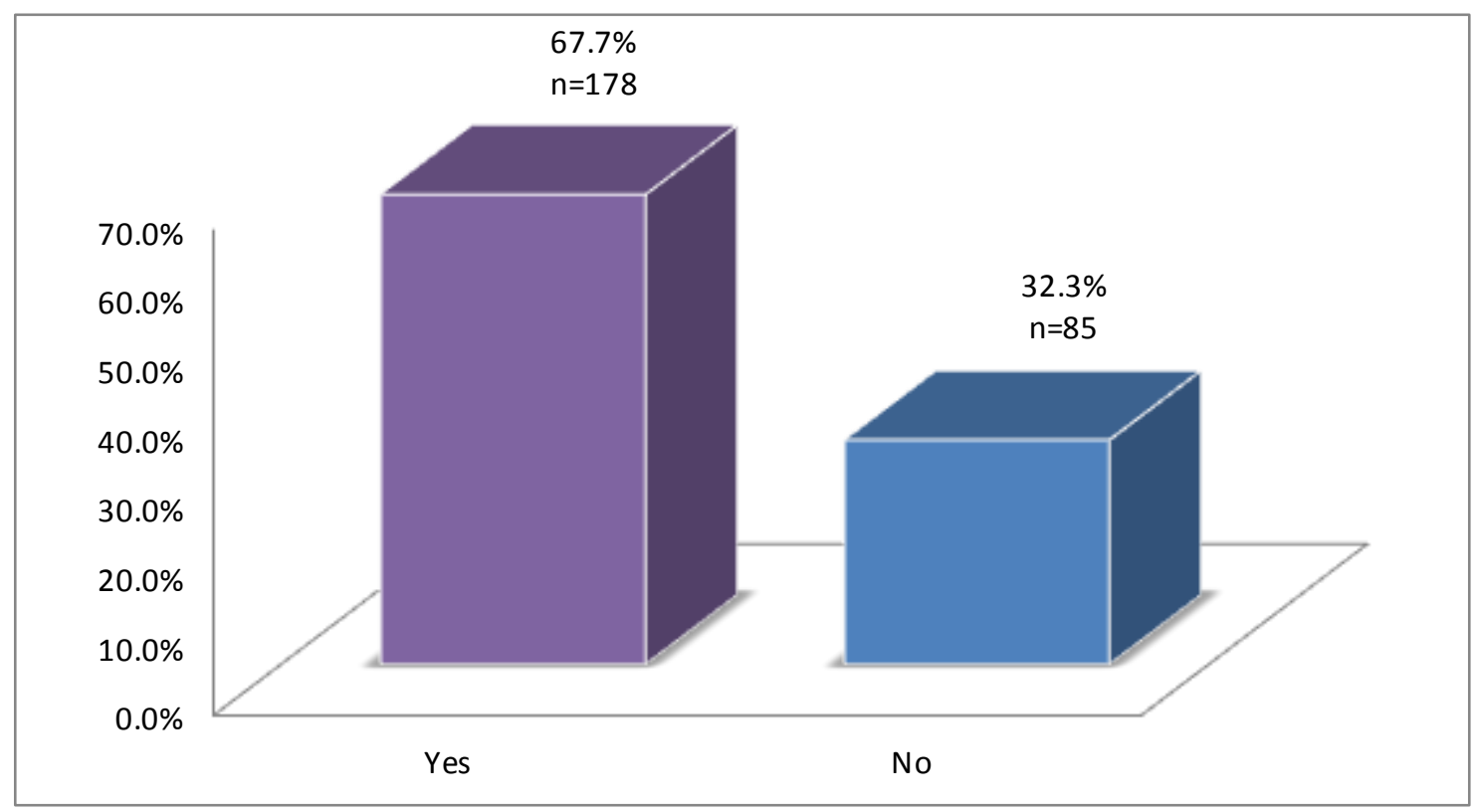


Respondents were then asked if they worked in a public health setting before the general supervision permit became available. The majority $(82.3 \%)$ of the respondents had not worked in a public health setting prior to obtaining the permit. Of the remaining respondents $(17.7 \%)$ who did work in a public health setting prior to obtaining their general supervision permit, $66.7 \%$ of them had paid positions. See Figure 18 and 19.

Figure 18: Previous Experience of Treating Patients in a Public Health Setting Before Acquiring the General Supervision Permit in Percent

$$
(\mathbf{n}=181)
$$

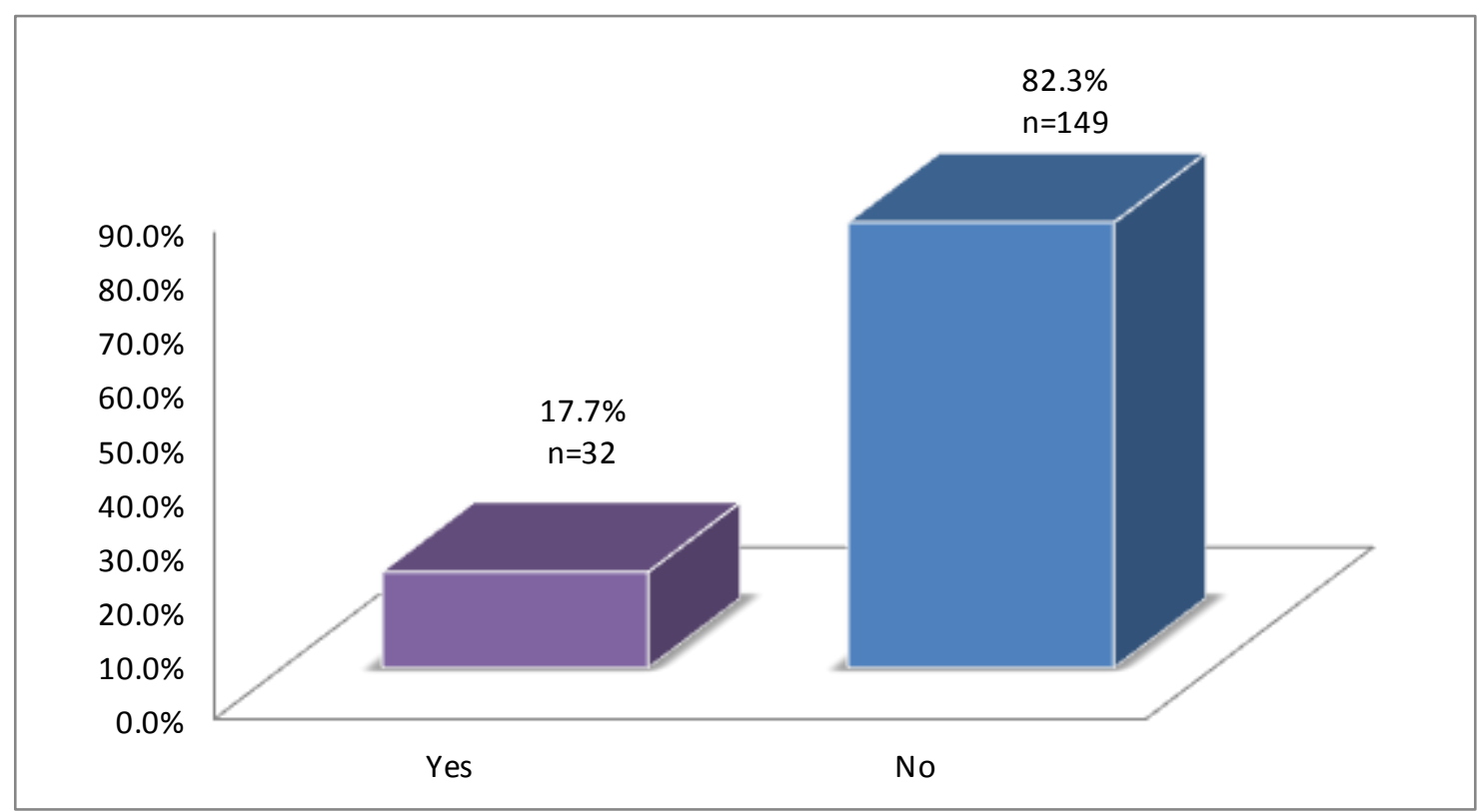


Figure 19: Type of Postion Held by Dental Hygienists Who Practiced in a Public Health Setting Before Acquiring the General Supervision Permit in Percent $(n=36)$

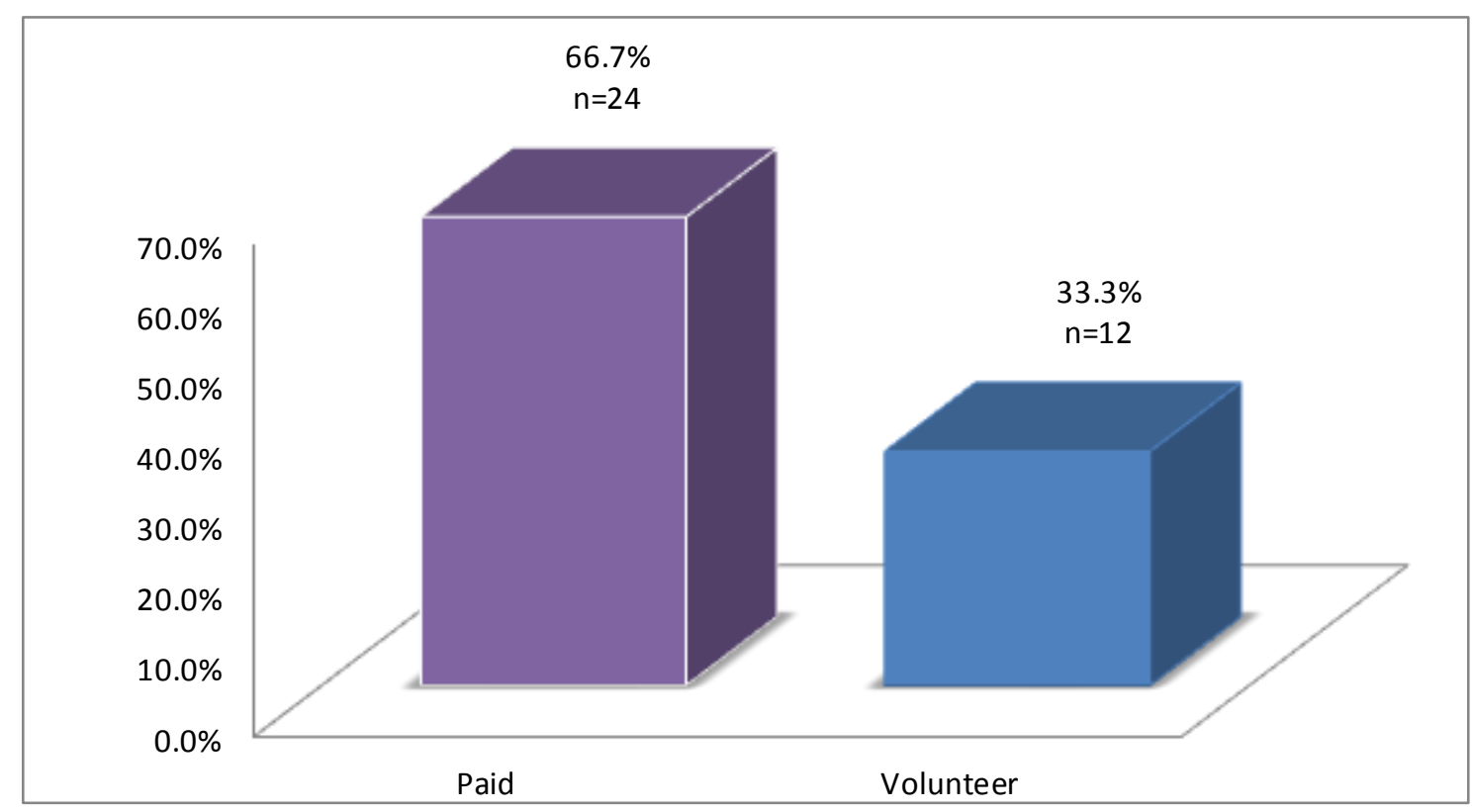

Less than $10 \%$ of respondents indicated that they are currently practicing in a public health setting and $59.1 \%$ of these respondents are utilizing the general supervision permit to treat patients. See Figure 20 and 21. 
Figure 20: Pecentage of Dental Hygienists with General Supervision Permit and Currently Treat Patients in a Public Health Setting $(n=180)$

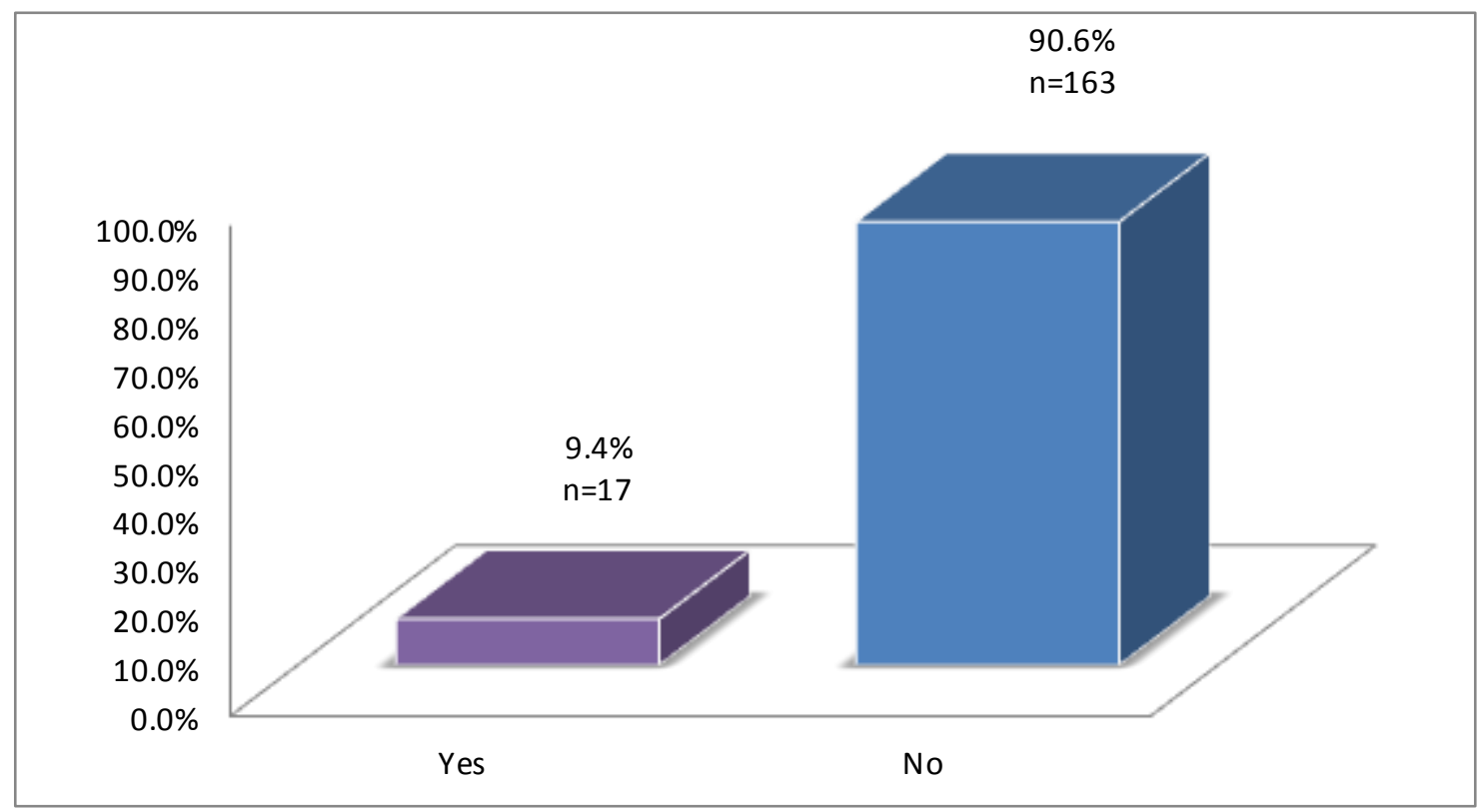


Figure 21: Permits Utilized by Dental Hygienists Treating Patients in a Public Health Setting in Percent $(n=22)$

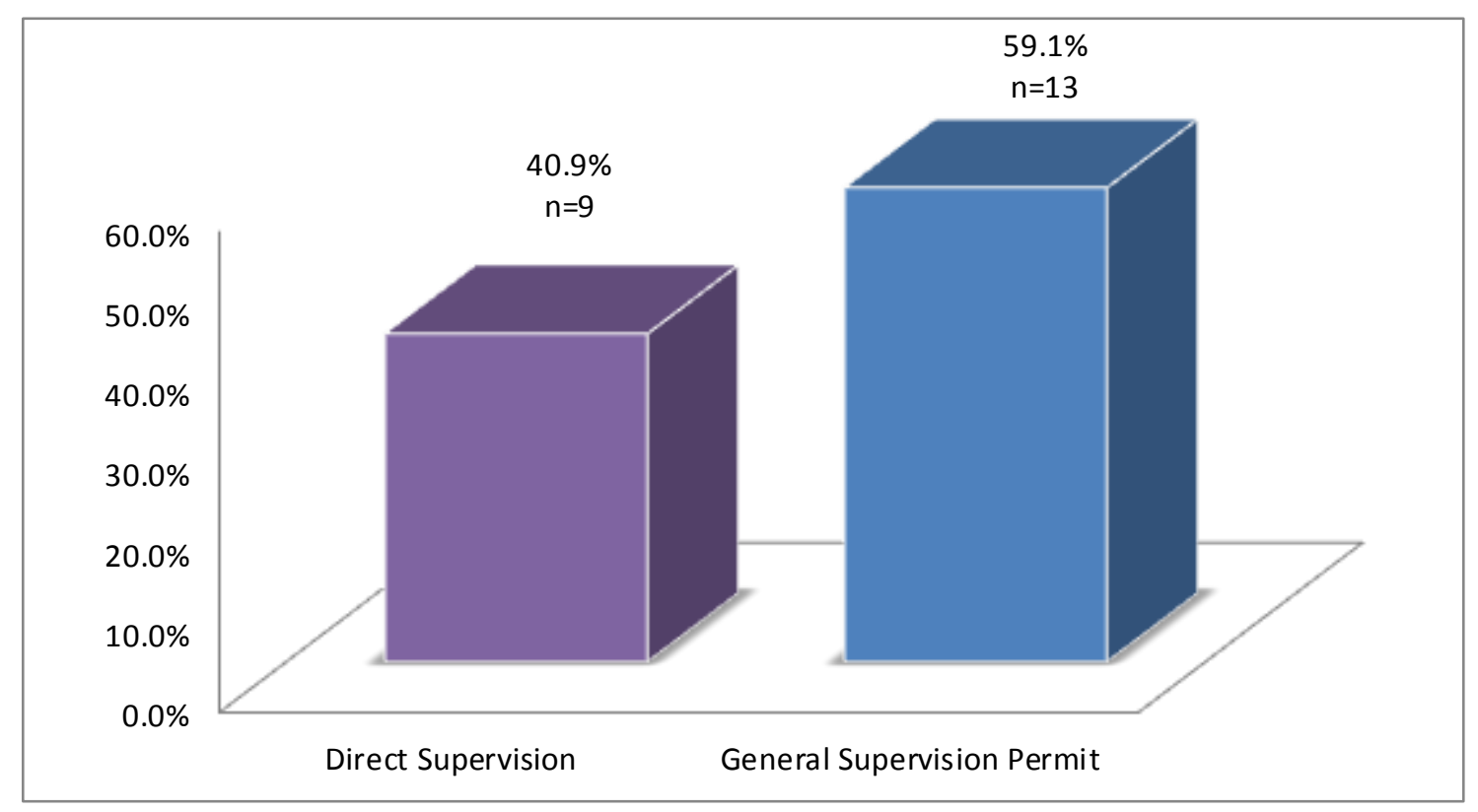

Respondents were asked what, if any, barriers existed that prevented them from treating patients in a public health setting. Almost half (49.5\%) of the respondents indicated that lack of job opportunities available was a barrier to working in a public health setting. The most common responses for the other category included currently working full-time, satisfied with present employer, and not interested in obtaining permits. See Figure 22. 
Figure 22: Barriers Preventing Dental Hygienists with the General

\section{Supervision Permit from Treating Patients in a Public Health Setting in}

Percent (n=196)

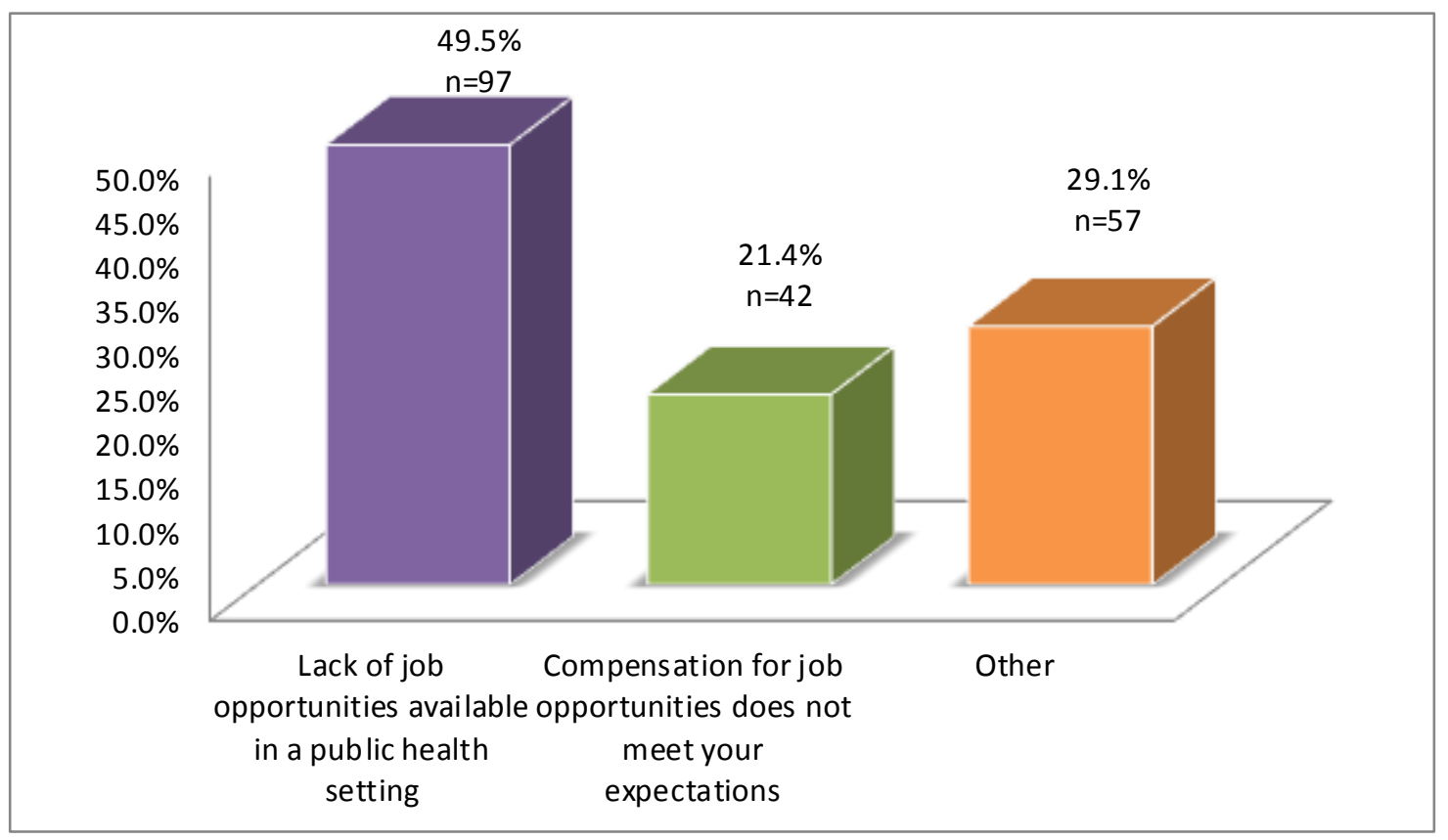

*Percentages do not equal 100 due to ability of respondents to check all that apply

The majority $(70.1 \%)$ of respondents utilizing the general supervision permit currently provide treatment to less than 10 patients per month. Only $9.6 \%$ of the dental hygienists who have the general supervision permit are providing treatment to 31 or more patients per month. See Figure 23. The respondents who are utilizing the general supervision permit are mostly treating patients in private dental offices (77.5\%). See Figure 24. 
Figure 23: Number of Patients Treated Monthly Utilizing the

General Supervision Permit in Percent $(n=167)$

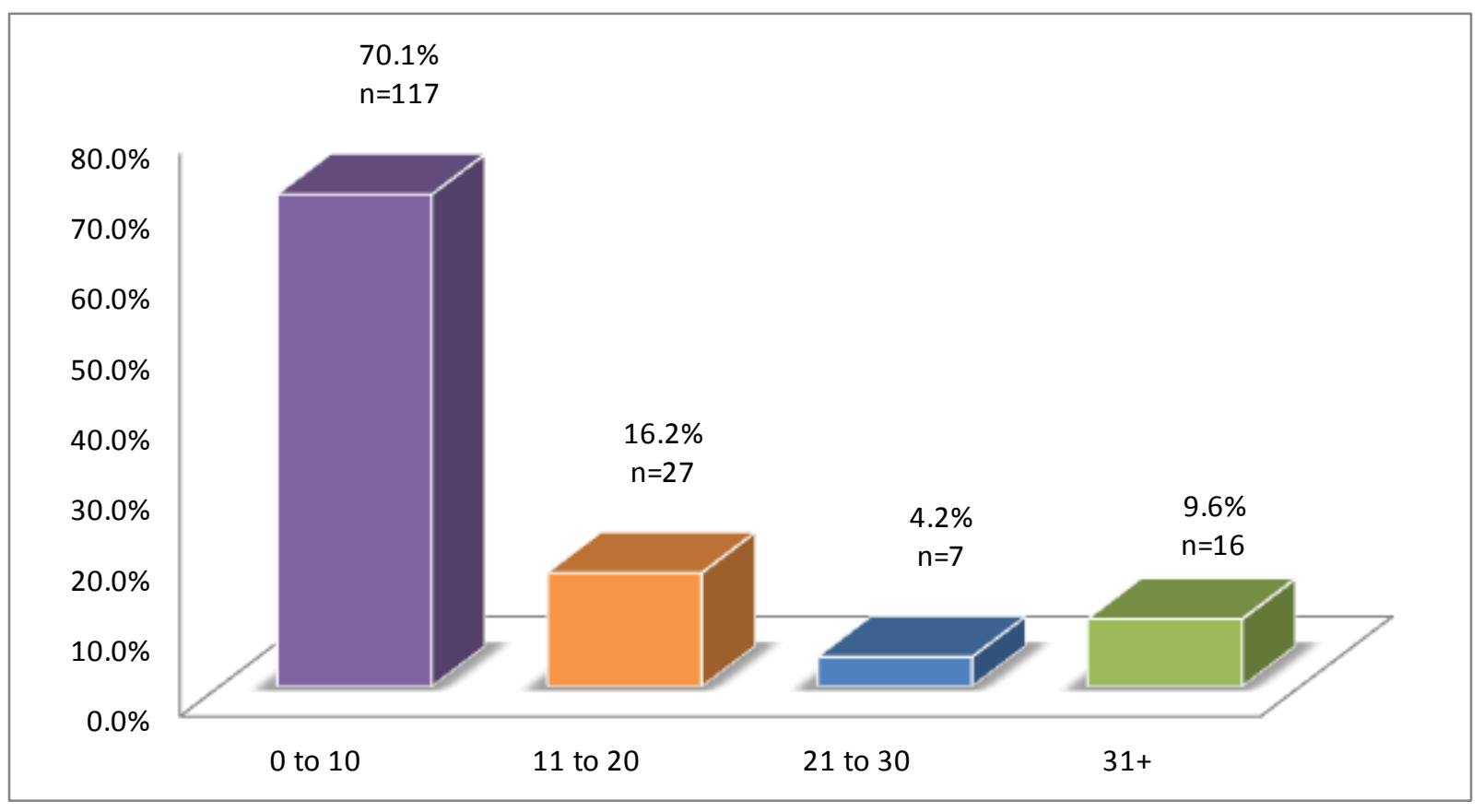


Figure 24: Practice Settings of Dental Hygienists Utilizing the General

\section{Supervision Permit in Percent $(n=187)$}

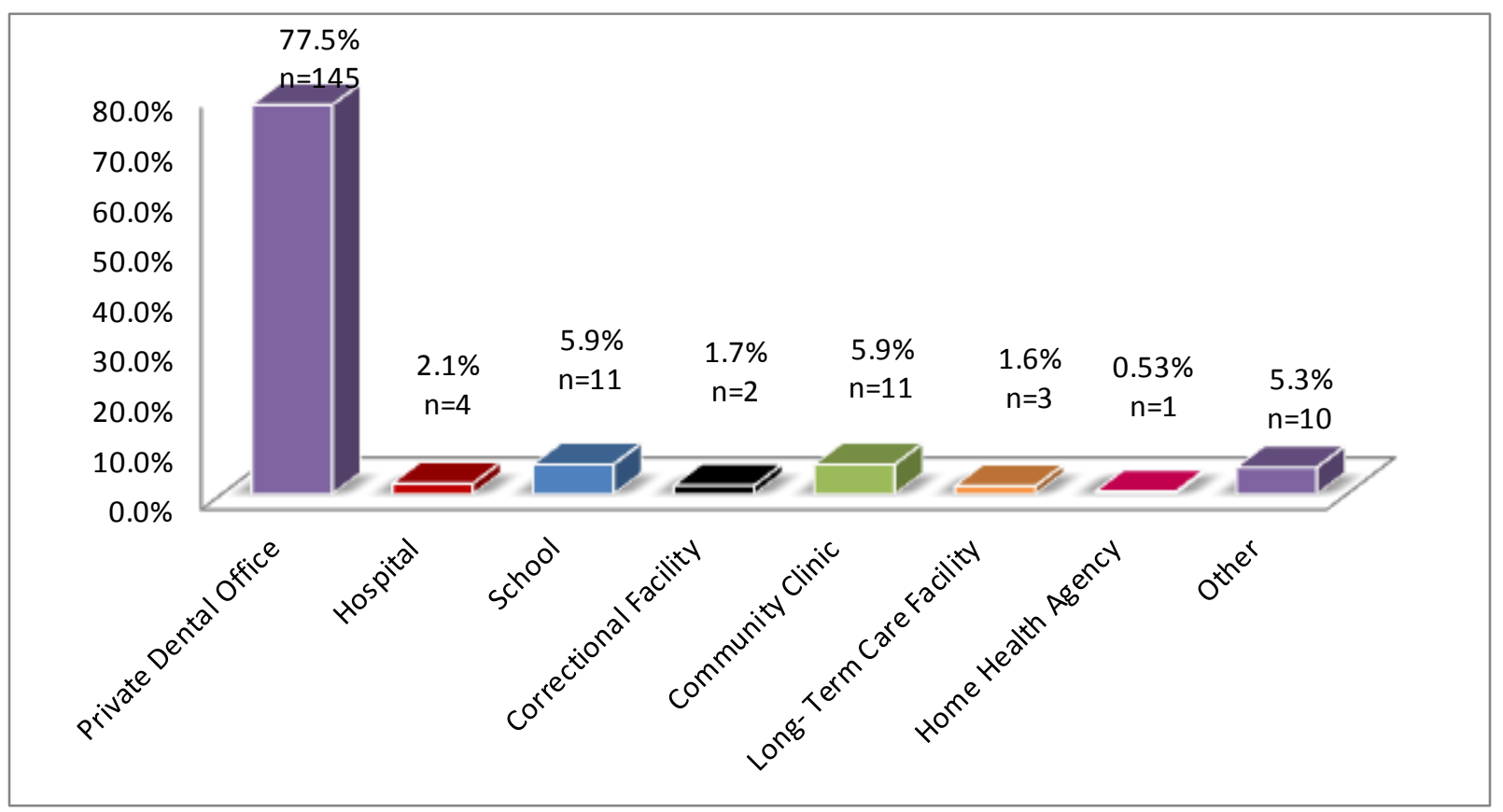

*Precentages do not equal 100 due to ability of respondents to check all that apply

Dental Hygienists who have obtained the general supervision permit were also asked what patient populations they treat in their office(s). Most of the respondents provide treatment to adults $(96.3 \%)$, senior citizens $(90.1 \%)$, and school aged children $(87 \%)$. The respondents also provide treatment to preschool children (63.4\%) and patients with medically compromising conditions (41.6\%). See Figure 25. 


\section{Figure 25: Patient Populations Treated by Dental Hygienist Utilizing the \\ General Supervision Permit in Percent $(n=161)$}

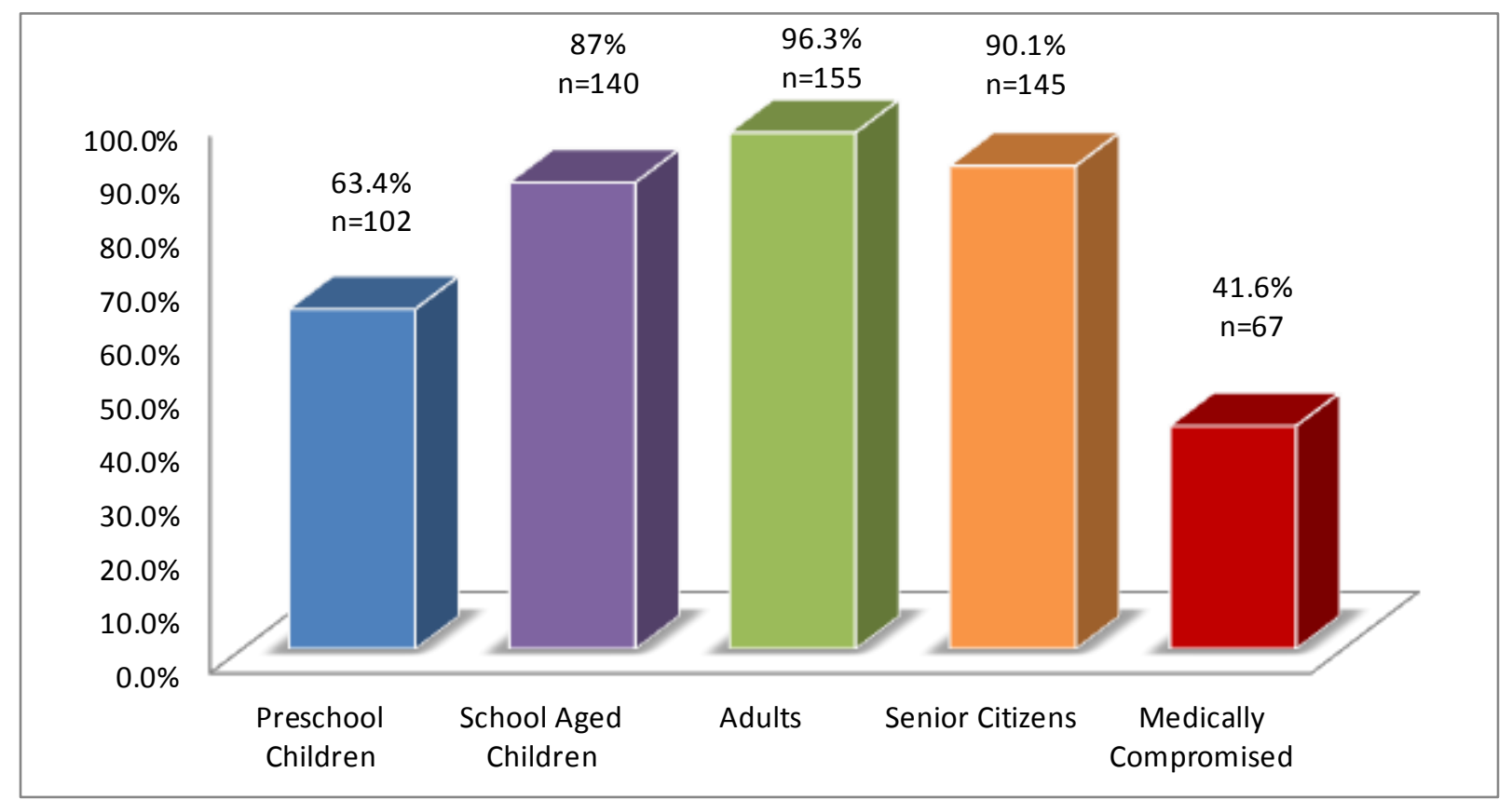

*Percentages do not equal 100 due to ability of respondents to check all that apply

Once again respondents who have obtained a general supervision permit were asked to indicate what dental procedures they provide. The majority of the respondents provide dental prophylaxis $(99.4 \%)$, provide dental health education $(98.1 \%)$, examine and record periodontal findings (96.3\%), and place, expose , develop and mount radiographs $(96.3 \%)$. Dental procedures currently not provided by most dental hygienists utilizing the general supervision permit include finishing and polishing restorations $(24.4 \%)$ and checking for and removing loose orthodontic bands and brackets (23.8\%). See Figure 26. 


\section{Figure 26: Types of Dental Procedures Provided Utilizing the General Supervision Permit in Percent $(n=160)$}

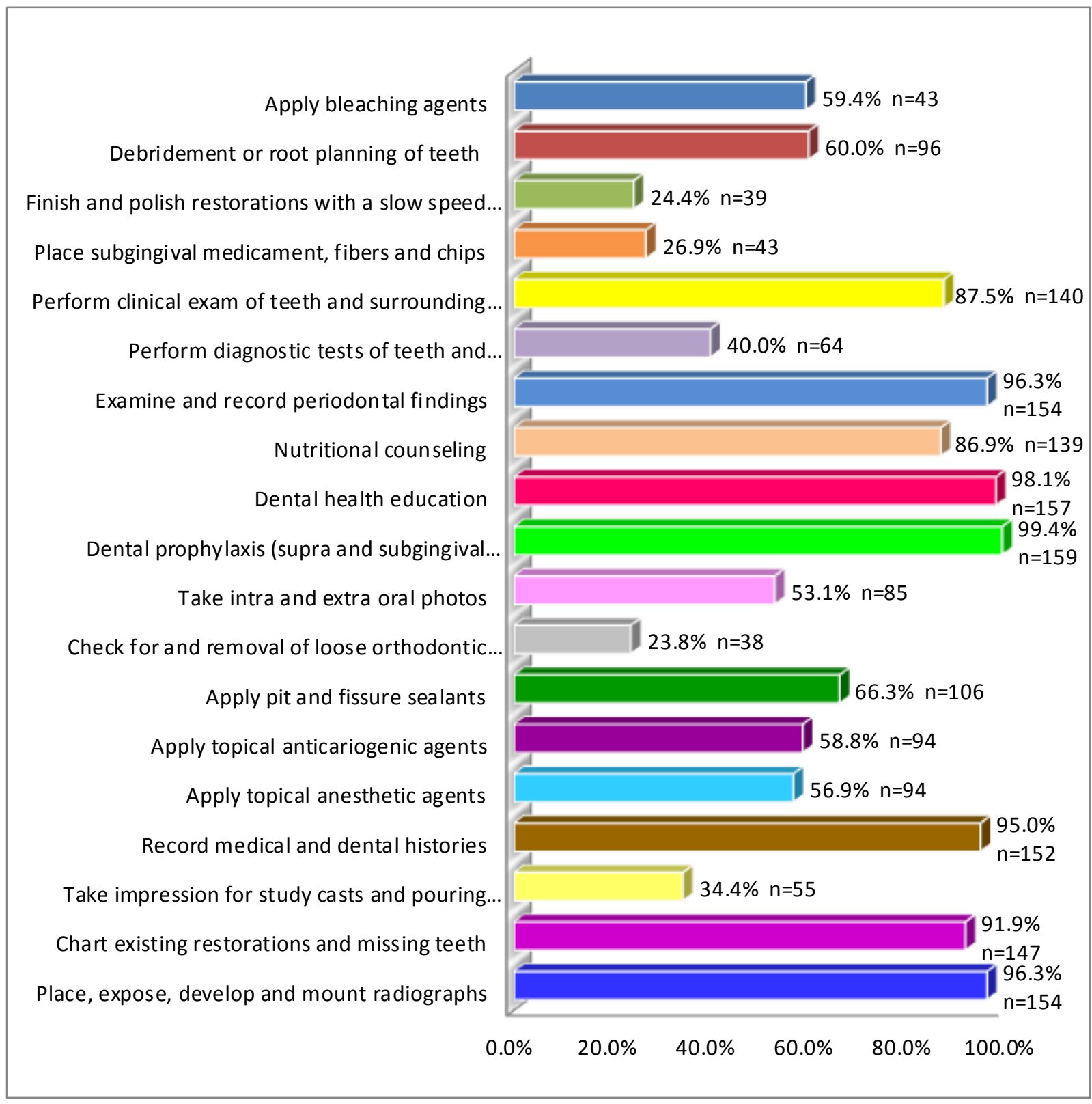

*Precentages do not equal 100 due to ability of respondents to check all that apply

Finally, respondents were asked to indicate if they felt that access to care has increased since the general supervision permit became available. The majority (43.9\%) of the dental 
hygienists respondedthat they did not know, approximately one third of the respondents answered affirmatively and the remainder (22.3\%) of the respondents replied "no." See Figure 27.

Figure 27: Opinion Regarding Effect the General Supervision Permit has on Access to Care in Percent $(n=269)$

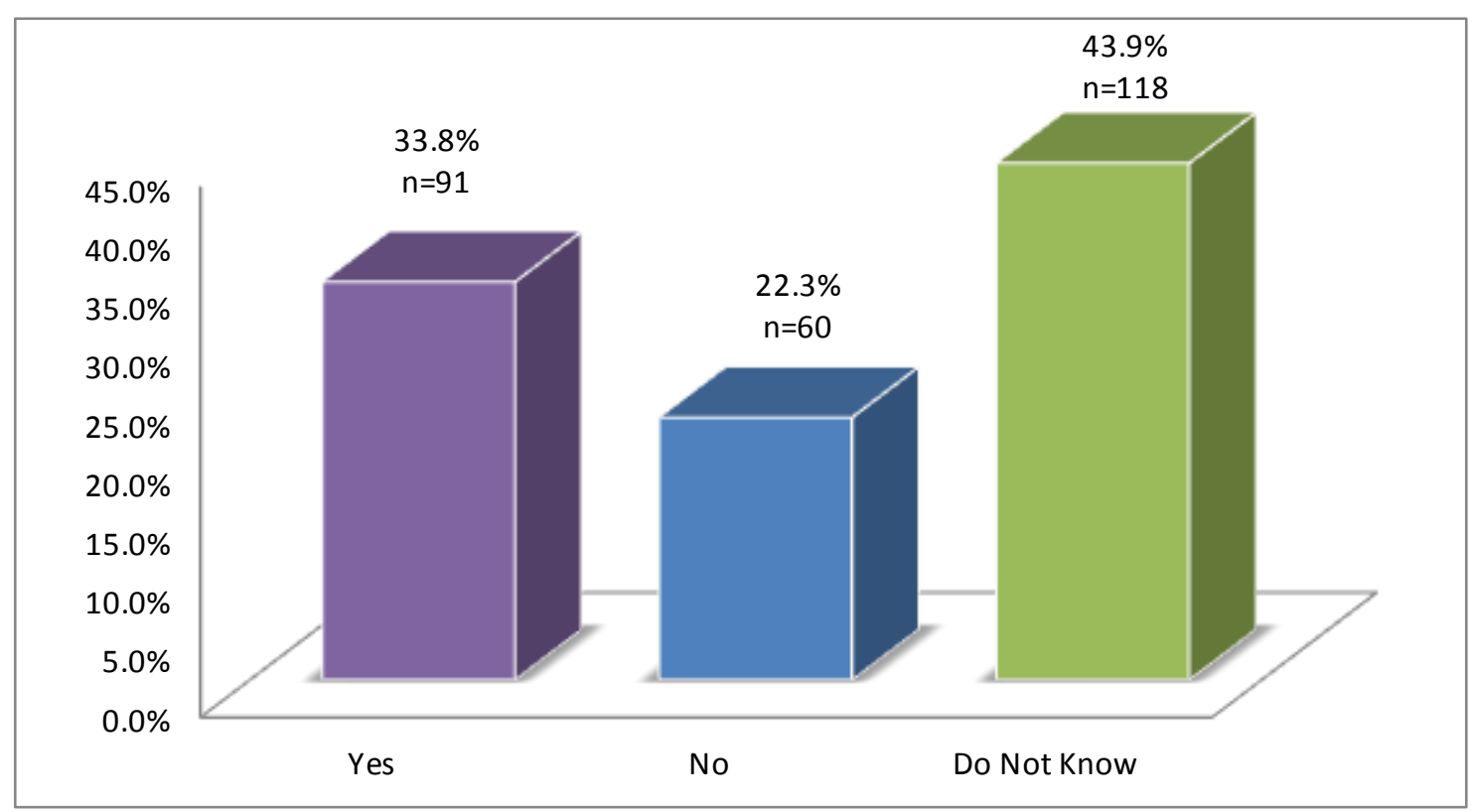




\section{DISCUSSION}

Access to care issues have been discussed in previously cited literature. Most areas struggle with access to dental care for all members of the population. The reason for implementing new dental hygiene permits such as general supervision and public health is to increase availability of dental services to the community. Some dental hygienists may obtain these permits but rarely if ever use them outside of a private dental practice.

The dental hygienists who responded to the survey indicated that only thirty- five of them currently have a public health dental hygiene permit. Most of them, twenty-two hygienists, reported they are currently not treating patients in a public health setting. The same thirty five dental hygienist also indicated that they believed access to care has increased since the public health dental hygiene permit became available. Although dental hygienists in West Virginia are currently obtaining the public health dental hygiene permit, it appears as though it is not being used to the fullest potential.

Dental hygienists who have obtained the public health dental hygiene permit but who are currently not treating patients in a public health setting indicated there were three main reasons why they are not treating in such settings. Lack of job opportunities and employer not being associated with a public health agency were two important barriers that prevent employment in a public health setting. Compensation for the job performed is also a barrier to obtaining public health employment. In order for access to care to increase and dental hygienists who have obtained the public health dental hygiene permit begin actively treating patients in a public health setting, several factors regarding employment need to change. In the future public health facilities need to evaluate their budget and hopefully allow for 
properly licensed dental hygienists to become employed in their facilities and therefore help improve access to care. The evaluation of the budget would allow facilities to find where changes can be made in order to hire dental hygienists to help with oral care. Budget and funding availability would allow the facilities to hire full or part time dental hygienists to help educate patients and all staff members about the importance of oral care and provide a system to help patients receive needed preventive oral care.

The general supervision permit is also available for properly trained dental hygienists to obtain. All of the respondents $(n=35)$ who stated they have obtained the public health dental hygiene permit have also obtained the general supervision permit. Dental hygienists who completed the survey indicated that 143 of them have the general supervision permit but not the public health dental hygiene permit. The question then arises regarding why the dental hygienists who have obtained the general supervision permit have no desire to obtain the public health dental hygiene permit. Perhaps these hygienists do not have a desire to work in a public health setting but have only obtained the general supervision permit to practice in private dental offices and educational settings.

Over one hundred (178) dental hygienists responded that they have obtained the general supervision permit. The dental hygienists also indicated that only $17(9.55 \%)$ of them are currently treating patients in a public health setting. Therefore of the 178 dental hygienists that responded, $161(90.45 \%)$ of them are not treating patients in a public health setting. Responding dental hygienists were also asked if access to care has increased since the general supervision permit became available. The majority ( 91 of the respondents or $51.12 \%$ ) of the 178 individuals who responded that they have obtained the general 
supervision permit also responded they believe access to care has increased. To reiterate, although the dental hygienists who have obtained the general supervision permit are primarily not treating patients in a public health setting, they do feel that access to care has increased since the development of the permit. Close to half ( 80 of the respondents or 49.08\%) responded that the main barrier to obtaining employment in a public health setting was lack of job opportunities available. Job opportunities for dental hygienists in public health settings are a major concern for many practicing hygienists. Obviously, based on how many hygienists have obtained the general supervision permit, many dental hygienists would like to work in a public health setting but positions are not available. Referring to topics discussed earlier, if public health settings could budget and gain funding to allow for dental hygienists to work in these facilities more positions could be created in the public health arena.

When dental hygienists were asked about improving access to care in West Virginia, several common topics arose in the responses. More clinics that allow adult dental care at an affordable price need to be provided. Adult coverage of Medicaid is also a popular topic regarding dental care. Respondents suggested that adults who have Medicaid insurance should be provided with some sort of dental care under the insurance program. Programs in schools and nursing homes should be developed according to respondents.

When asked about additional comments regarding the public health dental hygiene permit, respondents mostly had the same information to share. More information regarding the public health dental hygiene permit needs to be developed and issued by the West 
Virginia State Dental Board. Many dental hygienists responded that they did not know about the public health dental hygiene permit or the requirements needed to obtain the permit.

Dental hygienists were then asked about additional comments regarding the general supervision permit. Most dental hygienists who responded to the survey indicated that they are typically using this permit in a private dental office when the dentist is out of the office. Few respondents indicated that the main reason for obtaining this permit was to help increase access to care in public health settings.

A common theme when discussing barriers to job opportunities was simply the lack of available dental hygiene positions in public health settings. Compensation is also an issue with employment. The compensation for dental hygiene jobs in public health settings does not currently meet the expectations of dental hygienists. Many also responded that they did not know how to locate positions in the public health setting.

In all of the questions where dental hygienists were able to insert their own comments a common issue with communication and respect arose. The dental hygienist and dentist relationship is such an important key to the success of comprehensive care for the patients. Both dentists and dental hygienists need to strive to work together and make the office or public health setting a better place to work and provide care to the patients. Communication and respect from all professionals is the key to a successful working relationship.

Literature regarding some of the topics addressed in the survey is still in the process of being created. However, several articles have been published regarding mid-level providers. Mid-level dental providers and dental hygienists who have obtained the general 
supervision and public health dental hygiene permits can be compared using literature that is currently available. There is currently a debate regarding mid-level dental providers. Some dental professionals believe that mid-level providers have a great deal to offer the profession and others believe mid-level providers are more of a hindrance than help, as illustrated in the previous literature review. The general supervision and public health dental hygiene permits offer a comparable debate regarding the usefulness and uselessness of the permits. Some dental hygienists believe the permits have value and therefore are obtaining them and trying to find a position when the permits can be utilized. Other dental hygienists believe that either the permits are not useful or their current position does not require the permits to be obtained and therefore they are not obtaining them. More research needs to be conducted and analyzed in order to completely understand the benefits and costs of the general supervision and public health dental hygiene permits. 


\section{CONCLUSIONS}

Several conclusions can be formed as a result of the data from the study. Conclusions formed contain information pertaining to access to care, treatment of patients in public health settings, lack of job opportunities available in public health settings, and awareness of permits for dental professionals. Each conclusion will be discussed in the following paragraphs.

The general supervision and public health dental hygiene permit have led dental professionals to believe, right or wrong, that access to care is increasing in West Virginia. The majority of dental hygienists who responded that they have obtained the general supervision permit and/or public health dental hygiene permit stated that they also felt there was an increase in access to care since the initiation of the permits. Dental professionals feel as though access to care has increased even though the majority of responding dental hygienists reported that they are not currently treating patients in a public health setting.

Dental Hygienists who have obtained the permits are not treating patients in the public health arena. A total of 35 dental hygienists who have obtained the public health dental hygiene permit responded to the survey and of those 35 respondents, 22 stated they are currently not treating patients in a public health setting. Prior to the development of the public health dental hygiene permit only $26 \%$ of the responding dental hygienists were treating patients in a public health agency. After the initiation of the public health dental hygiene permit, $26 \%$ of the responding dental hygienists began treating patients in a public health setting. Therefore access to care did not increase as expected with the public health dental hygiene permit due to the fact only an additional $2 \%$ of the hygienists became actively 
involved in treating patients in a public health setting after obtaining the permit. A total of 178 dental hygienists who have obtained the general supervision permit responded to the survey and of those 178 respondents, only 17 reported that they are currently treating patients in a public health agency. Before the development and implementation of the general supervision permit $17.7 \%$ of the dental hygienists were treating patients in public health settings. After the initiation of the general supervision permit, less than $10 \%$ of the responding dental hygienists reported they were treating patients in a public health setting. Therefore the number of dental hygienists treating patients in a public health setting has declined since the installation of the general supervision permit.

Positions of employment are not available to dental hygienists in the public health arena. Almost half of the dental hygienists who have obtained the general supervision permit stated that a barrier to treating patients in public health settings is the lack of employment opportunities in these public health settings. Dental hygienists who have obtained the public health permit reported that lack of job opportunities in public health settings as well as their current employer not being associated with a public health agency are barriers to treating patients in a public health setting.

Many dental hygienists responded in the open ended questions that they feel as though more information needs to be published regarding both permits as well as more classes offered closer to their homes or offices. Apparently dental hygienists and dentists are not properly educated regarding the general supervision and public health dental hygiene permits and the prerequisites needed, functions, and places of employment intended for each permit. Once dental hygienists and dentists are educated more regarding the general 
supervision and public health dental hygiene permit, access to care could increase as well as dental hygienists beginning to utilize their dental hygiene permits in settings where the permit was intended to help patients.

\section{RECOMMENDATIONS}

Advancements in the West Virginia State Dental Law have occurred in the past several years. The addition of the public health dental hygiene permit and the general supervision permit have been a step forward to improving access to care for West Virginia residents. Dental hygienists who have obtained the general supervision and public health dental hygiene permits should be encouraged to practice in public health settings. The data concludes that currently dental hygienists are not actively treating patients in a public health setting. The new challenge for state legislature is to develop ideas and programs that would entice dental hygienists to work in the public health setting. Incentives for dental hygienists to work in the public health arena could be benefits (medical, dental, and vision insurance, and retirement plans), compensation, and possible tuition loan repayment. Access to care issues in West Virginia need to be addressed and providing qualified dental hygienists with some of the above incentives may help to expand the dental hygiene workforce and scope of practice and therefore lead to an increase in access to care.

Positions in the public health arena also need to be developed. Incentives are needed but first the positions for the qualified dental hygienists need to be formed. Legislation should focus on the development of such positions in public health setting. According to the 
dental hygienists who have obtained the general supervision permit, lack of job opportunities in public health settings in a major barrier to obtaining employment in the public health arena. The development of new jobs in these settings would allow this current barrier to be eliminated, partially or completely, for qualified dental hygienists.

Many dental hygienists who responded that they had obtained the public health dental hygiene permit indicated that their employer is not associated with a public health agency and therefore they are unable to provide treatment to patients in a public health setting. Dental hygienists need to be made aware that they do not need their employer to be associated with a public health agency in order to obtain employment in the public health setting. Dentists should also be encouraged to become affiliated with a public health agency where they can provide treatment to patients.

Compensation also was reported by the responding dental hygienists as a barrier to obtaining employment in a public health setting. Dental hygienists who have treated patients in the past in public health settings held paid positions. The public health arena needs to someone how develop a salary for dental hygienists working in public health settings that are comparable to what a dental hygienist may earn in private practice.

Awareness of the uses and prerequisites of the general supervision permit and the public health dental hygiene permit need to be issued to all dental professionals. Dental hygienists need to be educated about these permits, their purpose, and the continuing education courses that are needed. The continuing education courses also need to be offered in more areas, according to responding dental hygienists. Dentists also need to be educated 
on the general supervision permit and the public health dental hygiene permit in order to ensure their dental hygienists are utilizing the permit correctly.

Working relationships between dental hygienists and dentists need to be improved. Some of the responding dental hygienists feel as though they do not receive the respect they should from dentists. Some also feel as though they do not need to be watched over while providing treatment to patients in a public health setting. Communication and respect are keys to improving the relationships of dentists and dental hygienists.

Public health settings also need to be clearly defined. Dental hygienists may have a different idea of what public health settings actually entail. For example, a dental hygienist who is practicing in a private office but goes with the dentist once a week to work in a nursing home as part of their employment may or may not see the nursing home as a public health setting. Therefore is they do not view this as an activity of treating patients in a public health setting they may answer questions differently and possibly skew data.

\section{FUTURE RECOMMENDATIONS FOR STUDY}

- A study that would survey other states that also have the general supervision permit

- A study that would survey other states that also have the public health dental hygiene permit

- A study that would allow data from more than one mailing to be used for the results 
- A study that would compare dental hygienists who have obtained the general supervision permit with mid-level dental hygiene providers

- A study that would compare dental hygienists who have obtained the public health dental hygiene permit with mid-level dental hygiene providers

- Clearly define the parameters of a public health setting to include hospitals, schools, correctional facilities, jails, community clinics, long-term care facilities, nursing homes, home health agencies, group homes, state institutions, and Accredited Dental Hygiene Education programs 


\section{REFERENCES}

1. Hygiene related diseases. Available: www.cdc.gov. Accessed 3 April 2011.

2. State oral health profile. Available: www.cdc.gov Accessed 20 February 2011.

3. State oral health plan. Available: www.oralhealthwv.org Accessed 20 February 2011.

4. Rule for the West Virginia board of dental examiners. Available www.wvdentalboard.org Accessed 30 June 2010.

5. Lambert, D., George, M., Curran, A., Lee, J., Shugars, D. 2009. Practicing dental hygienists' attitudes toward the proposed advanced dental hygiene practitioner: a pilot study. The Journal of Dental Hygiene, 83(3), 117-125.

6. Lee, H.C., Alexander, M., Richard, B. 2009. Evolving profession of dental hygiene and career development. Access, May-June, 6-8.

7. Basile, S.V., Born, D.O. 2007, Dental hygiene workforce issues: a Minnesota study. The Journal of Dental Hygiene, 81(1), 11-23.

8. McKinnon, M., Luke, G., Bresch, J., Moss, M., Valachovic, R.W. 2007. Emerging allied dental workforce models: considerations for academic dental institutions. Journal of Dental Education, 71(11), 1476-1491. 
9. American academy of pediatric dentistry analysis and policy recommendations concerning mid-level dental providers. 2010. Pediatric Dentistry, 32(1), 21-26.

10. Nash, D.A. Expanding dental hygiene to include dental therapy: improving access to care for children. 2009. The Journal of Dental Hygiene, 83(1), 36-44.

11. Dollins, H., Gadbury-Amyot, C.C. 2008. The United Kingdom dental therapist program: lessons learned. Access, March, 6-19.

12. Elliot-Smith, S. 2009. Solving the access-to-care issue in Minnesota. Access, August, 14-19.

13. Gross-Panico, M. 2009. Affiliated practice dental hygiene. The Journal of Dental Hygiene, 83(4), 197-198.

14. Cosaboom, M. 2007. Expanding access to oral care for children in Arizona through affiliated practice dental hygiene. Access, January, 31-35.

15. Darby, M.L. 2009. The advanced dental hygiene practitioner at the master's-degree level: is it necessary. The Journal of Dental Hygiene, 83(2), 92-95.

16. Finkelman, R.D. 2009. The public health dental hygiene practitioner: an alternative perspective. Access, August, 26-35. 
17. Nash, D.A. 2009. Pediatric oral health therapists are important to address the access to care problem for children. Pediatric Dentistry, 31(7), 464-466.

18. Hinson, P. 2009. Mid-level providers are not in the best interest of children. Pediatric Dentistry, 31(5), 375-376.

19. Byrd, T.O. 2010. Alternative practice settings for dental hygienists-what does the future hold. Access, March, 2 and 32.

20. Caban-Martinez et al. 2007. Dental care access and unmet dental care needs among U.S. workers. Journal of the American Dental Association, 138, 227-230.

21. Fuente-Hernandez, J., Acosta-Gio, A.E. 2007. The effect of poverty on access to oral health care. Journal of the American Dental Association, 138, 1443-1445.

22. Gadbury-Amyot, C.C., Brickle, C.M. 2010. Legislative initiatives of the developing advanced dental hygiene practitioner. The Journal of Dental Hygiene, 84(3), 110-113.

23. Gaston, M.A. 2004. Dental hygienists and access to oral health care. The Journal of Dental Hygiene, 78(11), 323-324.

24. Naughton, D.K. 2009. The business of dental hygiene-a practice experience in nursing homes. The Journal of Dental Hygiene, 83(4), 193-194. 
25. Mitchell, J. 2008. Review of proposed oral health workforce models: part II. Access, Sep/Oct, $10-12$.

26. Nash, D.A., Nagel, R.J. 2005. Confronting oral health disparities among American Indian/Alaska Native children: the pediatric oral health therapist. American Journal of Public Health, 95(8), 1325-1329. 
Appendix A

IRB Exemption 
BRAAN2: IRB Protocol Marked as Exempt

To: afunk@hsc.wvu.edu, Igray1@mix.wvu.edu, cdebiase@hsc.wvu.edu, smorgan@hsc.wvu.edu, mhendryx@hsc.wvu.edu

Cc:

Date: 02:27 PM

From: wvuecomp@wvu.edu Reply-To:
Show/Hide

Security

Information

Bcc:

The following IRB Protocol has been marked as Exempt.

Tracking \#: $\mathrm{H}-22740$

PI: Funk, Amy

Title: Utilization of public health and general supervision permits by dental hygienists in West Virginia

The BRAAN2 website can be accessed by clicking the following link: BRAAN2 Login 


\section{Appendix B}

Dental Hygiene Permit Survey 


\section{Dental Hygiene Permit Survey}

Please mark only one correct response for each question unless otherwise indicated. If you answer other for any questions please explain on the line provided.

01. Are you actively practicing dental hygiene? Yes No

IF NO, PLEASE SKIP TO QUESTION 19

02. Do you currently have a Public Health Dental Hygiene permit for the state of West Virginia?

Yes

No

IF NO, PLEASE SKIP TO QUESTION 08

03. Were you involved with treating patients in a public health setting under direct supervision before you acquired the Public Health Dental Hygiene permit for West Virginia?

Yes

No

IF NO, PLEASE SKIP TO QUESTION 05

04. Was the position a paid or volunteer position?

Paid

Volunteer

05. Are you currently treating patients in a public health setting?

Yes

No

\section{IF NO, PLEASE SKIP TO QUESTION 07}

06. Are you treating these patients in the public health setting under direct supervision or by utilizing your Public Health Dental Hygiene permit?

Direct Supervision

SKIP TO QUESTION 08

Public Health Dental Hygiene permit

07. Check all barriers that currently prevent you from treating patients in public health settings.

Lack of job opportunities available in a public health setting Compensation for job opportunities does not meet your expectations Employer is not associated with any public health agencies Other: 
08. Do you currently have a General Supervision permit for the state of West Virginia? Yes No

IF NO, PLEASE SKIP TO QUESTION 14

09. Were you involved with treating patients in a public health setting under direct supervision before you acquired the General Supervision permit for West Virginia? Yes No

IF NO, PLEASE SKIP TO QUESTION 11

10. Was the position a paid or volunteer position? Paid Volunteer

11. Are you currently treating patients in a public health setting?

Yes

IF NO, PLEASE SKIP TO QUESTION 13

12. Are you treating these patients in the public health setting under direct supervision or by utilizing your General Supervision permit? Direct Supervision

\section{SKIP TO QUESTION 15} General Supervision permit

13. Check all barriers that currently prevent you from treating patients in public health settings.

Lack of job opportunities available in a public health setting Compensation for job opportunities does not meet your expectations Other:

\section{SKIP TO QUESTION 15}

14. If you do not currently have the Public Health Dental Hygiene permit or the General Supervision permit please check the reasons below that inhibit you from obtaining these licenses.

Prerequisites to obtain the permit have not been met No interest in obtaining these permit No job opportunities available Compensation for job opportunities does not meet your expectations Other: 
15. Please check the average number of patients you currently treat in a month and which license/permit you use when providing treatment.

Direct Supervision

0-10

11-20

21-30

$31+$
Public Health Permit

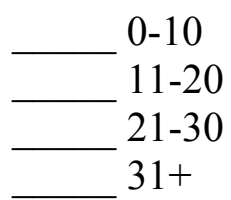

General Supervision Permit

$\begin{array}{ll} & 0-10 \\ & 11-20 \\ & 21-30 \\ & 31+\end{array}$

16. Please check all of the environments where you currently practice and which license/permit you use when practicing.

Direct Supervision

Private Dental Office

Hospital

School

Correctional Facility

Community Clinic

Long Term Facility

Home Health Agency

Other Setting: Please Specify:
Public Health Permit

Private Dental Office

Hospital

School

Correctional Facility

Community Clinic

Long Term Facility

Home Health Agency

Other Setting: Please Specify:
General Supervision Permit Private Dental Office Hospital School Correctional Facility Community Clinic Long Term Facility Home Health Agency Other Setting: Please Specify:

17. Please check all of the patient groups you treat and which license/permit you use when providing treatment.

Direct Supervision

Preschool Children

(Newborn to 4)

School Aged Children (5-18)

Adults (19-64)

Senior Citizens $(65+)$

Medically Compromised
Public Health Permit

Preschool Children

(Newborn to 4)

School Aged Children (5-18)

Adults (19-64)

Senior Citizens (65+)

Medically Compromised
General Supervision Permit

Preschool Children
(Newborn to 4)
School Aged Children (5-18)
Adults (19-64)
Senior Citizens (65+)
Medically Compromised


18. Please check all of the services you provide to patients under each of the licenses/permit listed.

\section{Direct Supervision}

Place, expose, develop and mount radiographs

Chart existing restorations and missing teeth

Take impressions for study and casts and pouring models Record medical and dental histories

Apply topical anesthetic agents Apply topical anticariogenic agents

Apply pit and fissure sealants

Check for and removal of loose orthodontic bands and brackets Take intra and extra oral photos Dental prophylaxis (supra and subgingival scaling and polishing) Dental health education

Nutritional counseling

Examine and record periodontal findings

Perform diagnostic tests of teeth and surrounding tissues

Perform clinical exam of teeth and surrounding tissues

Place subgingival medicament, fibers and chips

Finish and polish restorations with a slow speed hand piece

Debridement or root planing of teeth

Apply bleaching agents

Prepare a generalized oral screening and referral to a dentist
Public Health Permit

Dental health education

Nutritional counseling

Prepare a generalized oral screening and referral to a dentist

Apply fluoride

Chart existing restorations and missing teeth

Record medical and dental

histories

Examine and record periodontal

findings

Prophylaxis (supra and subgingival scaling and polishing)
General Supervision Permit

Place, expose, develop and mount radiographs

Chart existing restorations and missing teeth

Take impressions for study and casts and pouring models Record medical and dental histories Apply topical anesthetic agent Apply topical anticariogenic agents Apply pit and fissure sealants Check for and removal of loose orthodontic bands and brackets Take intra and extra oral photos Dental prophylaxis (supra and subgingival scaling and polishing) Dental health education

Nutritional counseling Examine and record periodontal findings

Perform diagnostic tests of teeth and surrounding tissues

Perform clinical exam of teeth and surrounding tissues

Place subgingival medicament, fibers and chips

Finish and polish restorations with a slow speed hand piece

Debridement or root planing of teeth Apply bleaching agents 
19. Do you think that access to dental care in West Virginia has increased since the Public Health Hygiene permit became available to dental hygienists?

\begin{tabular}{l} 
Yes \\
\hline No \\
\hline
\end{tabular}

20. Do you think that access to dental care in West Virginia has increased since the General Supervision permit became available to dental hygienists?

\begin{tabular}{l} 
Yes \\
\hline No
\end{tabular}

Do not know

21. Any additional comments regarding access to dental care in West Virginia can be expressed below.

22. Any additional comments regarding Public Health Dental Hygiene permit can be expressed below.

23. Any additional comments regarding General Supervision permit can be expressed below.

24. Any additional comments regarding barriers to job opportunities for dental hygienists in public health settings may be expressed below. 
Appendix C

Cover Letter First Mailing 
November 17, 2010

Dear Dental Hygienist,

I am currently pursuing a Master of Science degree in Dental Hygiene from West Virginia University. To partially fulfill the requirements of a master's thesis, I am conducting a survey of all dental hygienists licensed in the state of West Virginia. This research project is being conducted by Amy Funk, MSDH, Principal Investigator, Lyndsey Gray, BSDH, Dr. Christina DeBiase, Dr. Michael Hendryx and Dr. Susan Morgan.

The purpose of my research is to examine how dental hygienists in West Virginia treat patients in various types of practice settings. Questions also address barriers dental hygienists encounter when trying to practice in a public health setting.

Prior to completing the survey, please be aware of the following definitions:

Public health dental hygiene permit allows a dental hygienist to practice in a public health environment.

General supervision permit allows dental hygienists to provide care to patients while the dentist is out of the office for not more than fifteen consecutive business days.

Dental hygienists who have acquired either permit are allowed to perform all duties in subsection 8.4(c) of the West Virginia State Dental Board law (WV State Dental Board).

Direct supervision requires that a dentist be physically present while a dental hygienist treats patients.

All duties listed in subsection 8.2 and 8.3 of the West Virginia State Dental Board law can be performed by dental hygienists under direct supervision (WV State Dental Board).

Your participation in this research is voluntary. Refusal to participate will not negatively affect you or my standing as a student at West Virginia University. You are not required to answer all the questions, and may quit the survey at any time. All information that is obtained from the survey will be kept confidential and will be reported in generalities only. West Virginia University’s Institutional Review Board (IRB) has acknowledgement of this study on file. 
The survey will take approximately 15 minutes of your time. Please return the survey in the postage paid envelope on or before December 13, 2010.

Thank you for your time. Your help is greatly appreciated.

Sincerely,

Amy D. Funk, MSDH

Interim Director

Division of Dental Hygiene

School of Dentistry

Christina B. DeBiase, EdD

Associate Dean for Academic \& Postdoctoral Affairs

School of Dentistry
Lyndsey N. Gray, BSDH

Graduate Student

Division of Dental Hygiene

School of Dentistry

Susan Morgan, DDS

Clinical Assistant Professor

Department of Periodontics

School of Dentistry

Michael Hendryx, PhD

Associate Professor, Department of Community Medicine

Director, West Virginia Rural Health Research Center 
Appendix D

Cover Letter Second Mailing 
January 3, 2011

Dear Dental Hygienist,

I am currently pursuing a Master of Science degree in Dental Hygiene from West Virginia University. To partially fulfill the requirements of a master's thesis, I am conducting a survey of all dental hygienists licensed in the state of West Virginia. This research project is being conducted by Amy Funk, MSDH, Principal Investigator, Lyndsey Gray, BSDH, Dr. Christina DeBiase, Dr. Michael Hendryx and Dr. Susan Morgan. This is the second attempt to gather your responses to the survey. Your responses are extremely important and will help determine how dental hygienists are utilizing the various permits to practice dental hygiene. Your cooperation in returning this survey is greatly appreciated.

The purpose of my research is to examine how dental hygienists in West Virginia treat patients in various types of practice settings. Questions also address barriers dental hygienists encounter when trying to practice in a public health setting.

Prior to completing the survey, please be aware of the following definitions:

Public health dental hygiene permit allows a dental hygienist to practice in a public health environment.

General supervision permit allows dental hygienists to provide care to patients while the dentist is out of the office for not more than fifteen consecutive business days.

Dental hygienists who have acquired either permit are allowed to perform all duties in subsection 8.4(c) of the West Virginia State Dental Board law (WV State Dental Board).

Direct supervision requires that a dentist be physically present while a dental hygienist treats patients.

All duties listed in subsection 8.2 and 8.3 of the West Virginia State Dental Board law can be performed by dental hygienists under direct supervision (WV State Dental Board).

Your participation in this research is voluntary. Refusal to participate will not negatively affect you or my standing as a student at West Virginia University. You are not required to answer all the questions, and may quit the survey at any time. All information that is obtained from the survey will be kept confidential and will be reported in generalities only. West Virginia University's Institutional Review Board (IRB) has acknowledgement of this study on file. 
The survey will take approximately 15 minutes of your time. Please return the survey in the postage paid envelope on or before February 4, 2011.

Thank you for your time. Your help is greatly appreciated.

Sincerely,

Amy D. Funk, MSDH

Interim Director

Division of Dental Hygiene

School of Dentistry

Christina B. DeBiase, EdD

Associate Dean for Academic \& Postdoctoral Affairs

School of Dentistry
Lyndsey N. Gray, BSDH

Graduate Student

Division of Dental Hygiene

School of Dentistry

Susan Morgan, DDS

Clinical Assistant Professor

Department of Periodontics

School of Dentistry

Michael Hendryx, PhD

Associate Professor, Department of Community Medicine

Director, West Virginia Rural Health Research Center 


\section{VITA}

Lyndsey N. Gray

Date of Birth: 1985

Place of Birth: Morgantown, West Virginia

Degrees Awarded:

May 2011

Master of Science in Dental Hygiene

West Virginia University

May 2008

Bachelor of Science in Dental Hygiene

West Virginia University

Awards and Honors:

National Health Science Corps Scholarship for Rural Health 2007

Colgate Student Total Achievement Recognition Award 2008

Mary Sanders Memorial Merit Award 2008

Golden Key International Honour Society 2009

\section{Professional Employment:}

West Virginia University Implant Services Coordinator April 2010- Present

West Virginia University Graduate Assistant

Endodontic Clinic- Morgantown, WV 304-293-3417

Dr. Lynnel Beauchesne

July 2008-December 2009

Tunnelton, WV 304-892-4653

January 2010-Present

Dr. Lynnel Beauchesne

Tunnelton, WV 304-892-4653

Summer 2007 Externship 